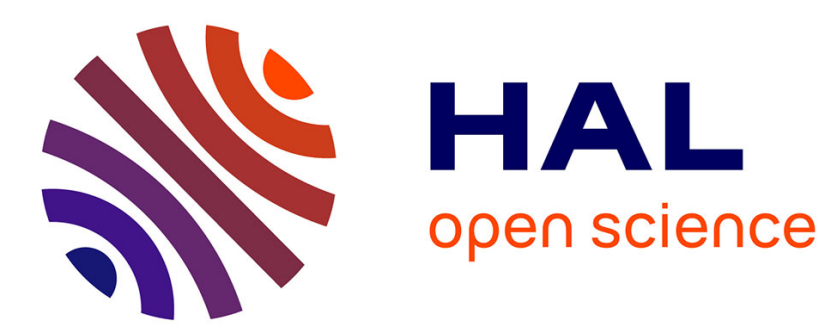

\title{
Process conditions for preparing well-defined nano-and microparticles as delivery systems of alkyl gallates
}

Asma Chebil, Denis Funfschilling, Jean-Luc Six, Cécile Nouvel, Alain Durand, Michèle Leonard

\section{- To cite this version:}

Asma Chebil, Denis Funfschilling, Jean-Luc Six, Cécile Nouvel, Alain Durand, et al.. Process conditions for preparing well-defined nano-and microparticles as delivery systems of alkyl gallates. Particuology , 2018, 44, pp.105-116. 10.1016/j.partic.2018.07.003 . hal-02105212

\section{HAL Id: hal-02105212 \\ https://hal.univ-lorraine.fr/hal-02105212}

Submitted on 6 Jun 2019

HAL is a multi-disciplinary open access archive for the deposit and dissemination of scientific research documents, whether they are published or not. The documents may come from teaching and research institutions in France or abroad, or from public or private research centers.
L'archive ouverte pluridisciplinaire HAL, est destinée au dépôt et à la diffusion de documents scientifiques de niveau recherche, publiés ou non, émanant des établissements d'enseignement et de recherche français ou étrangers, des laboratoires publics ou privés. 
SONICATION

$\downarrow$

EVAPORATION

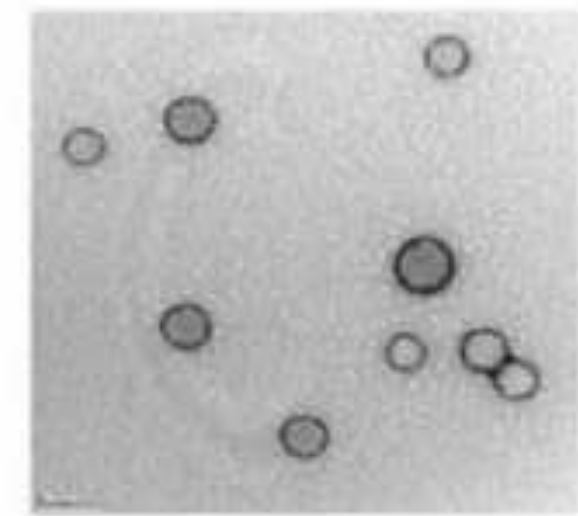

MICROFLUIDIC

FLOW-FOCUSING

DEVICE
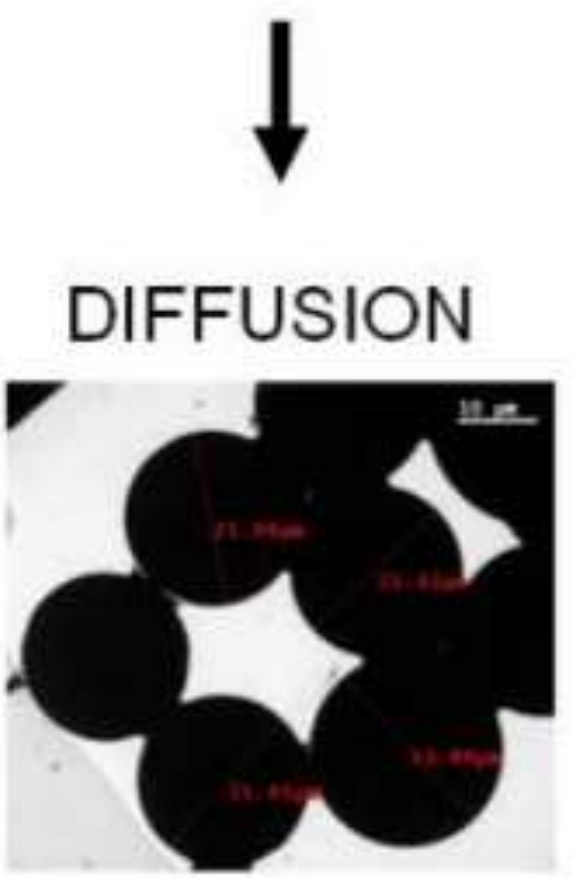

MECHANICAL

AGITATION

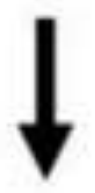

EVAPORATION

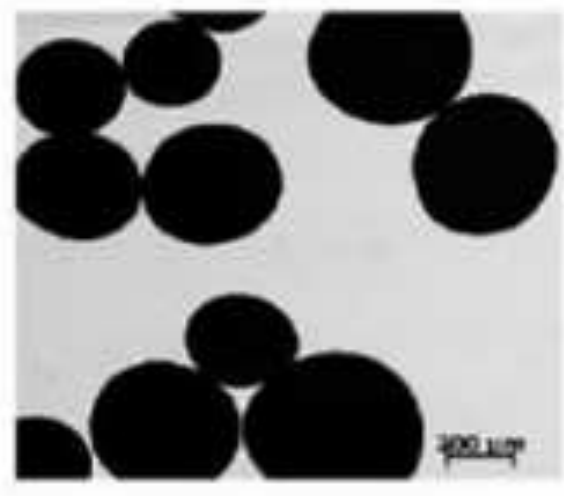

$100 \mu \mathrm{m}$

$1000 \mu \mathrm{m}$

$1 \mu \mathrm{m}$

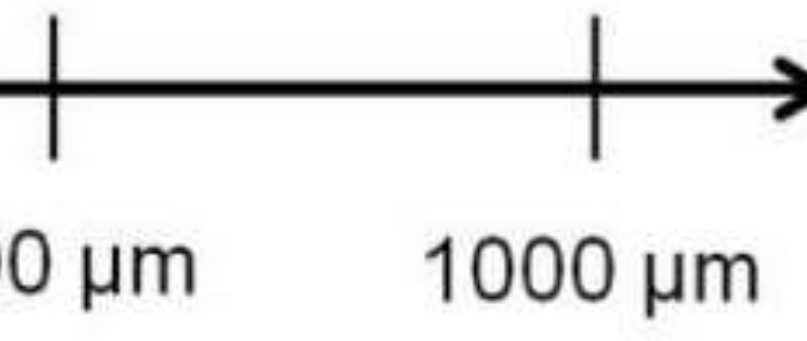




\section{Process conditions for preparing well-defined nano- and microparticles as delivery systems of alkyl gallates}

Asma Chebil ${ }^{\mathrm{a}}$, Denis Funfschilling ${ }^{\mathrm{b}, 1}$, Jean-Luc Six $^{\mathrm{a}}$, Cécile Nouvel ${ }^{\mathrm{a}, 2}$, Alain Durand ${ }^{\mathrm{a}}$, Michèle Léonard $^{\mathrm{a}, *}$

\section{Highlights}

- Suspensions of dextran-covered poly(D,L-lactide) particles were prepared.

- Emulsion/solvent evaporation (diffusion) process was used with dextran derivatives.

- Varying emulsification conditions led to a wide range of particle diameters.

- Encapsulation of alkyl gallates in each particle type was performed and evaluated.

- Release kinetics were monitored and compared according to the class of particles. 


\title{
Process conditions for preparing well-defined nano- and microparticles as delivery systems of alkyl gallates
}

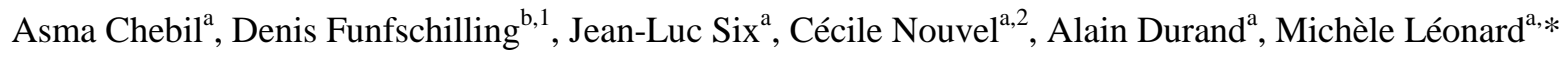 \\ ${ }^{a}$ Université de Lorraine, CNRS, LCPM, F-54000 Nancy, France \\ ${ }^{\mathrm{b}}$ Université de Lorraine, CNRS, LRGP, F-54000 Nancy, France \\ ${ }^{1}$ Present address: Université de Strasbourg, CNRS, ICube, F-67000 Strasbourg, France \\ ${ }^{2}$ Present address: Université de Lorraine, CNRS, LRGP, F-54000 Nancy, France \\ *Corresponding author. Tel: 33 (0)3 727437 02; Fax: 33 (0)3 833799 77; E-mail: michele.leonard@univ- \\ lorraine.fr
}

\begin{abstract}
Dextran-covered poly(D,L-lactide) (PLA) nano- and microparticles were prepared using an emulsion/solvent evaporation (or diffusion) process for the encapsulation of alkyl gallates (AGs). In the first step, a solution of PLA and AG in ethyl acetate was emulsified to give an aqueous phase containing a hydrophobically modified dextran, which acted as a stabilizer. The second step involved solvent evaporation or diffusion. The emulsification conditions were varied, which allowed for the preparation of nano- and microparticle suspensions covering a wide range of surface-average particle diameters from $0.1 \mu \mathrm{m}$ (sonication) to $500 \mu \mathrm{m}$ (stirring with a magnetic bar), with narrow and reproducible size distributions. Continuous microfluidic emulsification in a flow-focusing system led to well-defined microparticles, in the 10-50 $\mu \mathrm{m}$ range. Particles loaded with octyl gallate (OG) and nonyl gallate (NG) were obtained using the three processes, and we showed that the encapsulation efficiency of OG and NG varied significantly depending on the emulsification process. The effect of particle size on the mechanism of in vitro release of encapsulated AGs was investigated. The kinetics of release were controlled either by Fickian diffusion within the solid core or swelling and hydrolytic degradation of the PLA matrix, depending on the $\mathrm{pH}$ of the external medium.
\end{abstract}

Keywords: Emulsion/solvent evaporation, Dextran, Poly(D,L-lactide), Encapsulation, Release, Alkyl Gallate

\section{Introduction}

Polyesters are well established biomaterials that have been used in numerous applications, including the controlled release of therapeutic compounds such as drugs, proteins, and DNA (Ansary, Awang, \& Rahman, 2014; Dunne, Bibby, Jones, \& Cudmore, 2003; Kumari, Yadav, \& Yadav, 2010; Nottelet, Darcos, \& Coudane, 2015; Rizkalla, Range, Lacasse, \& Hildgen, 2006; Wischke \& Schwendeman, 2008). In the case of biomaterials, the ability to produce spherical particles with different sizes has been shown to present a significant opportunity for tailing materials to specific applications and different modes of administration, as well as modulating drug loading efficiency and the kinetics of release. Polymeric particles with different sizes can selectively accumulate in different target organs or tissues, therefore particle size and distribution play an important role in the preparation of particles for drug delivery. It is clear that, particle size has a 
pronounced impact on the efficiency of formulations and the optimal size range depends on the selected delivery route. The characterization of particle size distribution throughout the manufacturing process is therefore desirable (Gaumet, Vargas, Gurny, \& Delie, 2008; Peltonen \& Hirvonen, 2008).

There are numerous techniques available for measuring the size of particles, such as the Coulter method, photon correlation spectroscopy, light diffraction, and microscopy (Bowen, 2002). The optimal technique for a particular sample is generally determined by the particle diameter range. The rough measurement range for a Coulter counter is $1-500 \mu \mathrm{m}$. When using this method, care should be taken with regard to the aperture of the microchannels which are traversed by the particles. Alternatively, dynamic light scattering (DLS) is convenient for particles in the $0.01-1 \mu \mathrm{m}$ range, but is not adapted for suspensions containing larger particles because sedimentation affects the Brownian motion effect. The most widely used technique for determining size distribution is laser light diffraction $(0.02-3000 \mu \mathrm{m}$ range). However, care must be taken in interpreting the quantitative validity of the information, for instance in overestimation of small size populations in the case of broad size distributions, and assumptions on particle shape in the calculation of the particle size. Therefore, results should preferably be compared with those of other techniques such as microscopy to obtain fully reliable information.

In addition to particle size, the physical characteristics of the particle surface have been shown to be important for influencing behavior for all administration routes. Indeed, surface properties are directly involved in the phenomena responsible for particle aggregation, specific interactions with surrounding constituents, and the ease of suspension reconstitution after drying. In recent decades, remarkable progress has been made in the use of polysaccharides (Lemarchand, Gref, \& Couvreur, 2004) for controlling PLA surface properties; such as chitosan (Huang, Wan, Wang, \& Wu, 2013; Jiang, Tang, Chen, \& Ding, 2014), hyaluronic acid (Jeannot et al., 2013; Jeong et al., 2012; Laroui et al., 2007; Pitarresi et al., 2013; Yadav et al., 2007; Zille et al., 2010), cellulose (Chittasupho, Thongnopkoon, \& Kewsuwan, 2016; Guo, Wang, Shu, Shen, \& Sun , 2012), pullulan (Jeong et al., 2006), and dextran (Gavory et al., 2011; Laville et al., 2013; Ma et al., 2008; Nouvel, Dubois, Dellacherie, \& Six, 2004; Nouvel et al., 2009; Österberg et al., 1995; Poltorak, Durand, Léonard, Six, \& Nouvel, 2015). One benefit of using polysaccharide-covered particles, as compared with pegylated carriers, is the presence of numerous reactive groups within the superficial chains that allow for the chemical coupling of specific targeting ligands. In addition, some polysaccharides exhibit targeting properties to specific receptors in cells or tissues, such as CD44 in the case of hyaluronic acid.

We previously reported the preparation of nanometric and micrometric oil-in-water emulsions and PLA particles stabilized by amphiphilic polymers derived from polysaccharides (particularly from dextran, a nonionic bacterial polysaccharide) (Aumelas, Serrero, Durand, Dellacherie, \& Leonard, 2007; Covis, Baravian, Marie, \& Durand, 2015; Durand, Marie, Rotureau, Léonard, \& Dellacherie, 2004; Rotureau et al., 2006; Rouzes, Léonard, Durand, \& Dellacherie, 2003). Dextran was chosen as a model compound for evaluating the performance of polysaccharide-based stabilizers. The presence of a dense and thick 
superficial layer of hydrophilic loops at the surface of the oil droplets provided good colloidal stability and offered the possibility of further chemical functionalization owing to the reactive hydroxyl groups present at the surface. In addition, dextran-based stabilizers were efficient for ensuring re-dispersion of the particles after the lyophilization of the suspensions (Rotureau et al., 2006). More recently, we reported a systematic comparison of two elaboration processes for the preparation of dextran-covered PLA nanoparticles: nanoprecipitation (physico-chemical low energy process) and emulsion/solvent evaporation (high energy process) (Chebil, Léonard, Six, Nouvel, \& Durand, 2018b). In addition to characterizing the particle size distributions and surface coverage of both processes, their performances for the encapsulation and release of alkyl gallates (AGs) were evaluated and compared.

The aim of this study was to prepare and characterize dextran-covered PLA nano- and microparticles by emulsion/solvent evaporation (E/SE) or emulsion/solvent diffusion (E/SD) processes, with the general approach of using hydrophobically modified dextran derivatives as emulsion stabilizers, to obtain physical adsorption of dextran chains at the surface of the particles. The aim was to vary the average particle diameter over a wide range from 0.1 to $1000 \mu \mathrm{m}$ by modifying the conditions of the emulsification step, while maintaining narrow particle size distributions. Obtaining a series of particle suspensions with average diameters covering a wide range of values was expected to allow for control of the release kinetics of the encapsulated substances. Nano-sized particles were expected to provide fast release kinetics, while micronsized particles were targeted for extending release over longer periods of time. In the second part of this study, the encapsulation efficiency of alkyl esters of gallic acid (AGs) as well as their release kinetics were evaluated and compared as a function of particle size distribution. AGs have potent therapeutic properties, including antitumoral, antimicrobial, and antiviral properties, and are also potent antioxidants, acting as scavengers of reactive oxygen species (Fuentes et al., 2016; Lacatelly, Filippin-Monteiro, \& CreczynskiPasa, 2013; Maldonado et al., 2011; Rosso et al., 2006; Sergediene et al., 1999; Velasco, Holgado, Dobarganes, \& Marquez-Ruiz, 2009). However, to the best of our knowledge, there have been no reports of the encapsulation and release of AGs in nano- and microparticles, with the exception of our previous work on nanoparticles (Chebil et al., 2018b).

\section{Materials and methods}

\subsection{Materials}

Dextran T40 was purchased from Pharmacia (Uppsala, Sweden; manufacturer data: $\overline{M_{\mathrm{n}}} 35-45,000$ g/mol). All other chemicals were purchased from Aldrich (St Quentin Fallavier, France) and used without further purification. Dialysis membrane Spectra/Por (MWCO: 12-14 kDa) was obtained from Spectrum laboratories Inc. (Toronto, Canada).

\subsection{Hydrophobic modification of dextran}


Hydrophobic derivatives of dextran $\left(\operatorname{DexC}_{6}-\tau\right)$ were prepared as previously described (Durand et al., 2004; Rouzes et al., 2003). Typically, $10 \mathrm{~g}$ of dextran T40 were dissolved in $100 \mathrm{~mL}$ of dimethyl sulfoxide (DMSO). After $1 \mathrm{~h}$, the required amounts of tetrabutyl ammonium hydroxide (TBAOH) and 1,2epoxyoctane were added to the solution. The reaction medium was stirred over $48 \mathrm{~h}$ at room temperature. The crude reaction medium was then dialyzed against a 1:1 (v/v) mixture of deionized water/ethanol and then against deionized water. The modified dextran (Fig. 1) was finally recovered by freeze drying and

analyzed by ${ }^{1} \mathrm{H}$ NMR in DMSO- $\mathrm{d}_{6}$ to which a few drops of $\mathrm{D}_{2} \mathrm{O}$ were added. The substitution ratio $\tau(\%)$ was defined as the molar ratio of covalently attached alkyl groups to sugar units. The substitution ratio was calculated by $\tau=100 y /(x+y)$.

Fig. 1

\subsection{Preparation of $\mathrm{DexC}_{6}-\tau$ covered PLA particles by $\mathrm{O} / \mathrm{W}$ emulsion - solvent evaporation or diffusion}

\subsubsection{Emulsification by sonication followed by solvent evaporation}

An aqueous solution of $\operatorname{DexC}_{6}-\tau(10 \mathrm{~mL})$ was added to a solution of PLA in ethyl acetate (EA). The mixture was pre-emulsified by vortex mixing for $1 \mathrm{~min}$, then sonicated (pulsed mode, $50 \%$ active cycle) in an ice bath using a vibracell $600 \mathrm{~W}$ (Bioblock Scientific, Illkirch, France). The organic solvent was evaporated at $37{ }^{\circ} \mathrm{C}$ in a ventilated oven for $1.5 \mathrm{~h}$. Finally, the resulting suspension was centrifuged $(25,000$ $\mathrm{g}, 45 \mathrm{~min}$ ), and the collected nanoparticles were re-suspended in water and centrifuged again to fully remove the non-adsorbed $\mathrm{DexC}_{6}-\tau$. The procedure was repeated 3 times. After freeze drying, the particles were analyzed by ${ }^{1} \mathrm{H}$ NMR in DMSO- $\mathrm{d}_{6}$, to which a few drops of $\mathrm{D}_{2} \mathrm{O}$ were added, to determine the amount of $\mathrm{DexC}_{6}-\tau$ per g of PLA.

The AG-loaded PLA particles were prepared in a similar way, using PLA+AG mixtures dissolved in EA. The amount of adsorbed DexC $6_{6}-\tau$ and encapsulated AG per g PLA were determined by ${ }^{1} \mathrm{H}$ NMR analysis after complete dissolution in DMSO- $\mathrm{d}_{6}$.

\subsubsection{Emulsification by mechanical stirring followed by solvent evaporation}

Microparticles were prepared by adding solutions of PLA or PLA+AG in EA to an aqueous solution of $\operatorname{DexC}_{6}-\tau$ with magnetic stirring. The obtained particle suspensions were collected, purified, and characterized using the same procedure as for nanoparticles (section 2.3.1).

\subsubsection{Emulsification using a microfluidic flow-focusing device followed by solvent diffusion}

The microparticles were prepared as described elsewhere (Chebil et al., 2018a). A PDMS flowfocusing device was fabricated using a soft standard photolithographic process. Briefly, a layer of SU8 ${ }^{\circledR}$ 
negative resin was deposited on a silicon wafer by spin coating and then backed. This wafer was exposed to UV light through a mask, and then developed with a specific solvent. The SU8 ${ }^{\circledR}$ master was covered with PDMS $+10 \%$ curing agent and then cured in an oven at $60{ }^{\circ} \mathrm{C}$ for $1 \mathrm{~h}$. Finally, the PDMS was sealed to a borosilicate glass wafer. The flow-focusing system was formed of rectangular channels (width $180 \mu \mathrm{m}$, depth $47 \mu \mathrm{m})$.

The PDMS surface was hydrophilized in piranha solution (mixture of $30 \mathrm{wt} \% \mathrm{H}_{2} \mathrm{O}_{2}$ and $\mathrm{H}_{2} \mathrm{SO}_{4}$ 1:2 $\mathrm{v} / \mathrm{v}$ ) for $15 \mathrm{~min}$, followed by dipping in $1 \mathrm{M} \mathrm{KOH}$ solution for $15 \mathrm{~min}$ (Maji, Lahiri, \& Das, 2012). The continuous phase was composed of an aqueous solution of $\operatorname{DexC}_{6^{-}} \tau(5 \mathrm{~g} / \mathrm{L})$ saturated with $\mathrm{EA}$ and the dispersed phase was composed of EA containing PLA (10 g/L) or a mixture PLA+OG (10 g/L, 80/20, w/w). Finally, EA was removed by solvent diffusion in a large volume of water (Fu, Ma, Funfschilling, $\mathrm{Zhu}, \& \mathrm{Li}, 2012)$. The resulting suspensions were washed and filtered (1.2 $\mu \mathrm{m}$ mesh) and characterized as described above (section 3.2.1).

\subsubsection{Thermal analysis of AG+PLA mixtures}

Mixtures of PLA and AGs were prepared in $2 \mathrm{~mL}$ of acetone. The acetone was evaporated in a ventilated oven at $37^{\circ} \mathrm{C}$ and the obtained samples were further dried under vacuum for $24 \mathrm{~h}$. The thermal transitions of the AG+PLA mixtures were detected by modulated differential scanning calorimetry (mDSC) using a Q2000 (TA Instruments, USA). The heating rate was $5{ }^{\circ} \mathrm{C} / \mathrm{min}$ under nitrogen, and the temperature was varied from $-25^{\circ} \mathrm{C}$ to $200^{\circ} \mathrm{C}$.

\subsubsection{Particle characterization}

\subsubsection{Particle size distribution and $\operatorname{Dex}_{6}-\tau$ surface coverage}

Particle size distribution was determined using laser light scattering (Mastersizer 2000@, Malvern

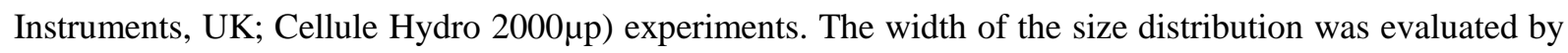
the Span value (Eq. (1)).

$$
\text { Span }=[(d(0.9)-d(0.1)] / d(0.5)
$$

In Eq. (1), $d(0.9), d(0.5)$, and $d(0.1)$ are the diameters at $90 \%, 50 \%$, and $10 \%$ cumulative volume, respectively.

The average particle diameter was evaluated by the surface-average diameter, noted $D[3,2]$, which also allowed the calculation of the specific area $\left(S_{\mathrm{p}}, \mathrm{m}^{2} / \mathrm{g}\right)$ of particles.

In what follows, the size distribution of particles will be characterized using the $d(0.5), D[3,2]$, and Span values. Generally speaking, the broader the distribution was (monomodal or multimodal), the higher the Span was. In the case of monomodal and narrow size distributions, the Span values were in the $0.8-1.5$ 
range. We observed that Span values higher than 1.5 corresponded to broad size distributions that combined submicronic particles and microparticles. The surface coverage of particles $\Gamma\left(\mathrm{mg} \mathrm{DexC}_{6}-\tau / \mathrm{m}^{2}\right.$ particle) was calculated based on ${ }^{1} \mathrm{H}$ NMR results and $S_{\mathrm{p}}$ values. For microparticles, it was not possible to determine the amount of adsorbed $\operatorname{DexC}_{6}-\tau$ because of the low $S_{\mathrm{p}}$ and thus the low ${ }^{1} \mathrm{H}$ NMR signals of adsorbed DexC $6^{-} \tau$ compared with the ${ }^{1} \mathrm{H}$ NMR signals of PLA.

\subsubsection{Monitoring in vitro release of AGs from nanoparticles}

After the washing step, the suspension of AG-loaded nanoparticles $(\sim 15 \mathrm{~mL})$ was separated into $2 \mathrm{~mL}$ aliquots and dialyzed against $2 \mathrm{~L}$ of deionized water at ambient temperature. As the solubility of $\mathrm{OG}$ and $\mathrm{NG}$ in water was very low (14 and $8.6 \mathrm{mg} / \mathrm{L}$, respectively, as determined by ${ }^{1} \mathrm{H} \mathrm{NMR}$ in $\mathrm{D}_{2} \mathrm{O}$ using phenol as an internal reference), the water phase was changed three times per day to avoid saturation of the solution and respect sink conditions. At various time points, aliquots were withdrawn and freeze dried. The amount of AG remaining in the particles was determined by ${ }^{1} \mathrm{H}$ NMR.

\subsubsection{Monitoring the in vitro release of AGs from microparticles}

AG release from microparticles was carried out in Tris/ $\mathrm{HCl}$ buffer $\mathrm{pH} 8.5$ to limit the acid-catalyzed hydrolysis of PLA over the long period (several months). In addition, $0.02 \mathrm{wt} \%$ of $\mathrm{NaN}_{3}$ was added to the buffer to prevent the development of microorganisms. Typically, samples containing $20 \mathrm{mg}$ of microparticles dispersed in $1 \mathrm{~mL}$ buffer were prepared and stirred at ambient temperature. The release medium was periodically removed and replaced with fresh buffer. At regular intervals, a sample was removed, washed, and analyzed by ${ }^{1} \mathrm{H}$ NMR to calculate the amount of AG remaining in the particles.

\subsubsection{Monitoring of PLA degradation during AG release from microparticles}

The potential degradation of PLA in AG-loaded microparticles over 120 days in the release medium (see section 2.3.5.3) was monitored by characterizing the molar mass distribution of PLA by size exclusion chromatography after dissolving a known mass of microparticles in tetrahydrofuran. The experimental device comprised a Waters 515 pump ( $1 \mathrm{~mL} / \mathrm{min})$ equipped with an inline degasser $\mathrm{AF}$, an injection loop, a pre-column, and three PLgel columns $5 \mu \mathrm{L}\left(300 \mathrm{~mm} \times 7.5 \mathrm{~mm}, 10^{2} \AA, 10^{3} \AA, 10^{4} \AA\right)$. The temperature was set at $40{ }^{\circ} \mathrm{C}$. Two detectors were used at the outlet: a differential refractometer OPTILAB rex (Wyatt Technology Corporation, USA) and a multi-angle laser light scattering detector mini Dawn Treos (Wyatt Technology Corporation) with wavelength of $658 \mathrm{~nm}$.

\subsubsection{Morphological studies of particles}

Morphological examination of nanoparticles and microparticles with diameters smaller than $100 \mu \mathrm{m}$ was performed by transmission electron microscopy (TEM) (CM200, Philips, Netherlands; $200 \mathrm{kV}$ ). Negative staining with uranyl acetate solution $(2 \mathrm{wt} \%)$ was carried-out for the nanoparticles. 
For the microparticles with diameters between 100 and $1000 \mu \mathrm{m}$, an optical microscope (Zeiss, Germany) equipped with a camera was used. One droplet of microparticle suspension was deposited onto the glass slide.

\section{Results and discussion}

\subsection{Fabrication of nano- and microparticles}

Our objective was to prepare and compare the properties of dextran-covered AG-loaded PLA particles with narrow size distributions and surface-average diameters in three ranges: $0.1-1 \mu \mathrm{m}$ (range 1), 1-100 $\mu \mathrm{m}$ (range 2), and 100-1000 $\mu \mathrm{m}$ (range 3). For ranges 1 and 3, emulsion/solvent evaporation was the procedure used for preparing particles. For range 2 emulsion/solvent diffusion was used. The lab-scale process of suspension fabrication essentially comprised three unit operations: emulsification, evaporation/diffusion of solvent, and washing (Fig. 2). The surface coverage of PLA/AG particles was obtained by physical adsorption of hydrophobically modified dextran derivatives at the oil/water interface during the emulsification step. Provided that the dextran derivatives acted as efficient stabilizers against aggregation and dilution, the size range of the final particles was essentially controlled by the emulsification step. Particles in range 1 were produced using sonication while particles in range 3 were obtained by mechanical stirring using a magnetic bar. Both were followed by solvent evaporation. The production of particles in range 2 was successfully achieved using a flow-focusing microfluidic system for the emulsification step, followed by dilution into a large excess of water. The operational parameters of the emulsification step for preparing well-defined particles with diameters within ranges 1 to 3 , were first defined without AG dissolved in the EA. The performances of the different particle suspensions were then evaluated and compared in terms of ability to reconstitute after freeze-drying, encapsulation efficiency, and kinetics of release of AGs.

Fig. 2

\subsection{Definition of operational parameters for each emulsification procedure}

\subsubsection{Production of nanoparticles (range 1) by sonication}

The influence of $\mathrm{DexC}_{6}-\tau$ substitution ratio was investigated first (Table 1). No significant difference in size distribution or amount of adsorbed polymer at the surface of the PLA nanoparticles $\left(\Gamma, \mathrm{mg} / \mathrm{m}^{2}\right)$, was observed between nanoparticles obtained using $\mathrm{DexC}_{6}-16$ or $\mathrm{DexC}_{6}-20$ as the stabilizer in the water phase. By contrast, an attempt to produce PLA nanoparticles using a more substituted polysaccharide, $\mathrm{DexC}_{6}-22$, was unsuccessful. Indeed, during the washing step (centrifugation), a significant amount of PLA particles covered with $\mathrm{DexC}_{6}-22$ irreversibly aggregated. This instability during centrifugation was attributed to excess hydrocarbon groups present within the superficial layer without direct contact with the PLA surface 
(Fournier et al., 1998). These hydrocarbon groups gave rise to particle aggregation upon particle concentration. For substitution ratios lower than $20 \%$, no aggregation was detected (Table 1).

Table 1

On the basis of previous results, all further experiments were carried out using $\operatorname{DexC}_{6}-\tau$ samples with $\tau$ between $16 \%$ and $20 \%$ dissolved in $10 \mathrm{~mL}$ of aqueous phase. The biphasic mixture was first agitated by vortex mixing for $1 \mathrm{~min}$, then sonication was carried out with a power input of $60 \mathrm{~W}$ over $2 \mathrm{~min}$, applied in pulsed mode. Various formulation parameters were also examined: concentration of PLA in EA, volume of organic phase emulsified, and concentration of $\mathrm{DexC}_{6^{-}} \tau$ in the aqueous phase (Table 2).

Table 2

Increasing the PLA concentration in EA above $150 \mathrm{mg} / \mathrm{mL}$ led to a significant increase in the average particle diameter and a broadening of the particle size distribution. At such PLA concentrations, a strong increase in the viscosity of the organic phase was visually detected. On the basis of PLA average molar mass and the Mark-Houwink relation, the critical overlap concentration in EA at $25{ }^{\circ} \mathrm{C}$ was estimated to be between 15 and $20 \mathrm{mg} / \mathrm{mL}$ (Garlotta, 2001). Thus, for concentrations higher than $150 \mathrm{mg} / \mathrm{mL}$ (i.e. ten times higher than the critical overlap concentration), the PLA solution in EA was in the semi-dilute entangled domain (Graessley, 1980). The resulting viscoelastic properties of the organic phase affected the emulsification procedure and were the origin of the broadening of the particle size distribution. In addition, for that series of experiments, the surface coverage of PLA particles after the washing steps showed values between 2.3 and $3.3 \mathrm{mg} / \mathrm{m}^{2}$ regardless of the PLA concentration in EA, confirming that the broadening of the particle size distribution was not a consequence of a default of droplet/particle stabilization by $\mathrm{DexC}_{6^{-}}$ 20 during emulsification. Conversely, the two other parameters - the volume of the organic phase and the concentration of $\mathrm{DexC}_{6}-20$ in the aqueous phase - both affected the stability of the intermediate oil-inwater emulsion.

When the volume ratio of the organic phase to aqueous phase was increased, larger PLA particles were obtained after solvent evaporation. For a volume ratio of 8:10, the Span value increased significantly and a multi-modal size distribution was obtained (Table 2). For volumes of EA higher than $8 \mathrm{~mL}$, the formation of a polymer film at the surface of the aqueous phase was visually observed during the evaporation step, indicating a lack of dispersion stability, which was attributed to insufficient surface coverage of oil droplets during the emulsification step. Considering that the surface coverage of the final PLA particles was not significantly modified, the formation of a broader particle size distribution was attributed to the increased probability of coalescence events during emulsification. When the concentration of $\mathrm{DexC}_{6}-20$ in the aqueous phase was reduced from 20 to $1 \mathrm{mg} / \mathrm{mL}$, the surface-average diameter of the particles increased, as well as the Span of particle size distribution, particularly for $\mathrm{DexC}_{6}-20$ concentrations lower than $5 \mathrm{mg} / \mathrm{mL}$, because of a lack of amphiphilic polymer to cover the surface of the 
PLA particles. In a previous report on the preparation of PLA nanoparticles using the E/SE process with similar conditions, it was shown that each solid particle formed during evaporation resulted from a single liquid droplet (Desgouilles, et al., 2003). Starting from this assumption, the relationship between initial droplet diameter and final particle diameter after EA evaporation was deduced (Eq. (2)).

$$
D_{\text {droplet }}=D_{\text {particle }} \times\left(1+\rho_{\mathrm{PLA}} /[\mathrm{PLA}]\right)^{1 / 3} .
$$

In Eq. (2) $D_{\text {droplet }}$ and $D_{\text {particle }}$ are the diameters of the initial liquid droplet and of the final particle $(\mathrm{nm})$, respectively, $\rho_{\text {PLA }}$ is the density of PLA $(1.25 \mathrm{mg} / \mathrm{mL})$ and $[\mathrm{PLA}]$ is the concentration of PLA ( $\mathrm{mg}$ of PLA per $\mathrm{mL}$ of EA). The maximum possible surface coverage of oil droplets during the emulsification step could be estimated from the loaded masses of DexC6-20 and PLA. The total surface area of oil droplets was approximated using the surface-average diameter of PLA particles after evaporation $(D[3,2])$ in Eq. (2), and by considering that the number of droplets was the same as the number of particles after evaporation (Eq. (3)).

$$
\Gamma_{\text {drop }}^{\text {max calc }}=\left[\mathrm{DexC}_{6}-20\right] \times V_{\mathrm{aq} \text { phase }} \times \rho_{\mathrm{PLA}} \times D[3,2] /\left(6 \times[\mathrm{PLA}] \times V_{\mathrm{EA}} \times\left(1+\rho_{\mathrm{PLA}} /[\mathrm{PLA}]\right)^{2 / 3}\right) .
$$

In Eq. (3) $V_{\text {aq phase }}$ and $V_{\mathrm{EA}}$ are the volume of aqueous phase and ethyl acetate respectively (mL), [DexC $\left.{ }_{6}-20\right]$ is the concentration of $\operatorname{DexC}_{6}-20$ in the aqueous phase $(\mathrm{mg} / \mathrm{mL})$, and $\Gamma_{\text {drop }}^{\text {calc }}$ is the maximum possible surface coverage of oil droplets (in $\mathrm{mg}$ of $\mathrm{DexC}_{6}-20 \mathrm{per}^{2}$ of droplet surface). When plotting the surface-average particle diameter after evaporation versus the maximum possible surface coverage of oil droplets, two main tendencies were found for all experimental conditions (Fig. 3). For the large majority of process conditions experimental points followed a common trend with $D[3,2]$ varying roughly as the inverse of $I_{\text {drop }}^{\text {max calc }}$. This was interpreted as a consequence of limitation of particle size by the stability of the intermediate oil-in-water emulsion, which was directly related to the amount of $\mathrm{DexC}_{6}{ }^{-}$ 20 available for covering the interface. Only three sets of experimental conditions-the highest concentrations of PLA in EA-led to points that deviated from this behavior. For these conditions, the final particle size was controlled by the rheological behavior of the organic phase rather than by the coverage of the interface during emulsification.

Fig. 3

Freeze-drying of aqueous nanoparticle suspensions for storage in solid form followed by reconstituting the samples by simple addition of water and gentle stirring, is an important property to investigate for potential practical applications. Direct freeze-drying of aqueous suspensions of PLA nanoparticles led to irreversible aggregation despite the presence of the superficial layer of $\mathrm{DexC}_{6}-\tau$ stabilizer (Rotureau et al., 2006). However, the addition of a cryoprotectant, trehalose, to the aqueous phase before freeze-drying (10 mg of trehalose per $1 \mathrm{~mL}$ of suspension) allowed perfect reconstitution of the suspensions with a particle size distribution identical to that obtained after the washing steps (data not 
shown). Literature data indicated that the amount of trehalose could possibly be reduced, however this was not investigated further for this work (Fonte et al., 2012; Saez, Guzman, Molpeceres, \& Aberturas, 2000).

\subsubsection{Production of microparticles (range 3) by mechanical stirring}

To produce very large PLA microspheres, sonication was replaced with mechanical agitation with a magnetic stirrer bar in the emulsification step, with the rest of the process remaining unchanged. Approximating the beaker and the magnetic bar as perfect cylinders, the ratios of the dimensions of the stirrer to those of the liquid phase were 0.89 and between 0.26 and 0.51 (depending on the experimental conditions), respectively (Fig. 4). The effects of several process conditions on the particle size distribution (surface-average particle diameter and Span) were investigated: agitation speed, concentration of PLA in EA, and oil-to-water volume ratio (Table 3).

Fig. 4, Table 3

The agitation speed and the oil-to-water volume ratio were the most efficient operational parameters for controlling the final surface-average particle diameter while maintaining sufficiently low Span values (Table 3) (Sansdrap \& Moës, 1993). The effect of PLA concentration in EA was similar to that found when using sonication instead of mechanical stirring (see section 3.2.1). When the PLA concentration reached $150 \mathrm{mg} / \mathrm{mL}$, a small amount of polymer was deposited onto the magnetic stirrer bar during emulsification. This deposit was removed before size measurements. This observation was explained by difficulties fractionating the organic phase because of its rheological behavior. The same upper limit of PLA concentration in EA was found with sonication (see section 3.2.1).

Optical micrographs of microparticle suspensions confirmed the spherical shape of the particles, the absence of aggregates, and the average particle diameters found by laser granulometry (Fig. 5).

Fig. 5

Because of the low specific area of the microparticles, the $\mathrm{DexC}_{6}-16$ adsorbed at their surface could not be detected. Nevertheless, we obtained indirect evidence of its presence. First, an oil-in-water emulsion was formed by mechanical agitation. Second, no aggregation of particles was detected during the washing step. Finally, the aqueous suspensions of microparticles could be freeze-dried and reconstituted with identical particle size distributions without any addition of cryoprotectant in the aqueous phase (data not shown).

\subsubsection{Production of microparticles (range 2) using a microfluidic flow-focusing device}

The preparation of microparticle suspensions with well-defined size distributions in range 2, was achieved using a continuous emulsification step involving a microfluidic flow-focusing device (MFFD). The MFFD incorporated flows of two immiscible fluids in microchannels. The continuous aqueous phase 
(containing $\mathrm{DexC}_{6}-\tau$ stabilizer, with flow rate $Q_{\mathrm{c}}$ ) was injected through two outside channels and the dispersed organic phase (containing PLA at a concentration of $10 \mathrm{mg} / \mathrm{mL}$, with flow rate $Q_{\mathrm{d}}$ ) was injected through a central channel (Fig. 6). Fluid dynamics at the flow-focusing region governed droplet break up, where droplets of the dispersed phase were produced as a result of the laminar shear stress and interfacial tension at the fluid-fluid interface (Bauer, Fischlechner, Abell, \& Huck, 2010; Chen, Erb, \& Studart, 2012; Keohane, Brennan, Galvin, \& Griffin, 2014; Khan, Serra, Anton, \& Vandamme, 2013; Kim et al., 2014, Martin-Banderas et al., 2005; McDonald, 2000; Peltonen \& Hirvonen, 2008; Pessi, Santos, Miroshnyk, Yliruusi, \& Mirza, 2014; Seemann, Brinkmann, Pfohl, \& Herminghaus, 2012; Serra et al., 2013). Emulsification in the MFFD was followed by dilution in a large excess of water. The detailed design of the process and the specificities of using macromolecular DexC $\mathrm{C}_{6}-\tau$ stabilizers are described in a specific paper (Chebil et al., 2018a). Here, we focused on the impact of the $Q_{\mathrm{c}} / Q_{\mathrm{d}}$ ratio of flow rates on the microparticle characteristics (Table 4). For $Q_{\mathrm{c}} / Q_{\mathrm{d}}$ ratios higher than or equal to 20, suspensions of micrometric particles with Span values lower than 1 were obtained. At that point, it was necessary to find a compromise between selecting experimental conditions that produced narrow particle size distributions (which would lead to a minimized $Q_{\mathrm{d}}$ ) and ensuring the production of sufficient particles for further applications (which would require maintaining a sufficiently high $Q_{\mathrm{d}}$ ). Thus, we selected $Q_{\mathrm{d}}=0.3 \mathrm{~mL} / \mathrm{h}$ and $Q_{\mathrm{c}}=6 \mathrm{~mL} / \mathrm{h}$. These conditions led to well-defined particles with diameters of around $20 \mu \mathrm{m}$. The size of the droplets formed at the outlet of the MFFD was found to be $108 \mu \mathrm{m}$. Taking into account the concentration of PLA, Eq. (2) led to an estimated particle diameter of $22 \mu \mathrm{m}$ after EA diffusion. This was in good agreement with the experimental values and confirmed the absence of particle aggregation during the diffusion step.

Fig. 6, Table 4

Finally, we verified that an aqueous suspension of microparticles (with $Q_{\mathrm{d}}=0.3 \mathrm{~mL} / \mathrm{h}$ and $Q_{\mathrm{c}}=6$ $\mathrm{mL} / \mathrm{h}$ ) could be freeze-dried and reconstituted without adding cryoprotectant. After reconstitution, the particle size distribution was identical to that found after the washing step (data not shown). TEM micrographs confirmed the spherical shape of the microparticles, the absence of aggregates, and the average diameter found by laser granulometry (Fig. 7).

Fig. 7

\subsection{Encapsulation of AGs within each class of PLA particles}

\subsubsection{Miscibility of AGs with PLA and their solubility in the aqueous phase}

Drug solubility in aqueous and organic media as well as its physical state within the solid particle matrix, have generally been considered major parameters in the design of encapsulation processes. Octyl gallate (OG), nonyl gallate (NG), and lauryl gallate (LG) were selected because of their hydrophobicity and low solubility in water. The physical state of AGs inside PLA was assessed by mDSC analysis of solid mixtures. The thermogram of neat PLA displayed a thermal transition at $52.9{ }^{\circ} \mathrm{C}$ corresponding to the tabulated glass transition temperature $\left(T_{\mathrm{g}}\right)$. Melting endotherms were observed at $90,82.5$, or $75{ }^{\circ} \mathrm{C}$, with 
neat OG, NG, or LG, respectively. For mixtures of AG and PLA, thermograms exhibited no fusion endotherm and a single $T_{\mathrm{g}}$ lower than that of bulk PLA provided that the weight fraction of AG was lower than $30 \mathrm{wt} \%$ for OG, $25 \mathrm{wt} \%$ for NG, or $10 \mathrm{wt} \%$ for LG. This was interpreted as the signature of molecularly dispersed AGs within the solid matrix. For mixtures containing higher weight fractions of AGs, fusion endotherms were detected, resulting from phase separation because of limited miscibility. As a result of its low miscibility with PLA, LG was not further investigated for encapsulation in PLA. Finally, we checked the potential hydrolysis of OG and NG ester groups after encapsulation in PLA nanoparticles. ${ }^{1} \mathrm{H}$ NMR monitoring showed that no ester group hydrolysis could be detected over a $144 \mathrm{~h}$ period at room temperature.

It has been shown that AGs such as OG can be solubilized into surfactant micelles in aqueous medium and modify their shape and other characteristics (Heins, Garamus, Steffen, Stöckmann, \& Schwarz, 2006). In addition, $\operatorname{DexC}_{6}-\tau$ polymers with $\tau$ close to $20 \%$ have been shown to form aggregates combining several macromolecules even in dilute solutions (Rotureau, Chassenieux, Dellacherie, \& Durand, 2005). Thus, ${ }^{1} \mathrm{H}$ NMR analysis was used to determine the maximum solubility of OG and NG in the presence of $\mathrm{DexC}_{6}-21$ and $\mathrm{DexC}_{6}-18$, respectively, at concentrations up to $10 \mathrm{mg} / \mathrm{mL}$ in water. A roughly linear increase was observed for both systems (Fig. 8), which was interpreted as resulting from the accumulation of the AG molecules in the hydrophobic core of $\mathrm{DexC}_{6}-\tau$ aggregates. By assuming a perfect linear variation and calculating the amount of hydrocarbon chains corresponding to each $\operatorname{DexC}_{6}-\tau$ concentration, it could be estimated that these aggregates contained one molecule of $\mathrm{OG}$ per $3 \mathrm{C}_{6}$ chains and one molecule of $\mathrm{NG}$ per $8 \mathrm{C}_{6}$ chains. It is clear that this increase in solubility was unfavorable for encapsulation in PLA particles, particularly in the case of microparticles produced by the microfluidic process (range 2) because of the ratio of flow rates between the organic and aqueous phases.

Fig. 8

\subsubsection{Encapsulation of AGs into particles produced by different processes}

\subsubsection{Encapsulation into nanoparticles (range 1) produced by sonication}

Two process parameters in particular were examined, the weight ratio of AG to PLA in the initial load $\left(W_{\mathrm{AG}}^{i}\right)$, and the total amount of PLA+AG in the organic phase $\left(M_{\mathrm{tot}}\right)$. The mean diameter of particles obtained after evaporation was poorly influenced by $W_{\mathrm{AG}}^{i}$ and $M_{\mathrm{tot}}$ under our experimental conditions (Table 5). Nevertheless, after the washing steps particle aggregation was observed for the highest values of $M_{\text {tot }}$ and $W_{\text {AG }}^{i}$ leading to excessively high values of Span (for OG and NG). For sufficiently low values of $M_{\text {tot }}$ and $W_{\text {AG }}^{i}$ the loaded nanoparticles exhibited similar characteristics (diameter and surface coverage) to those prepared with PLA alone. The encapsulation efficiency of OG and NG in nanoparticles was generally lower than $50 \%$ in conditions that did not lead to particle aggregation during washing (Table 6). This was explained by the solubilization of $\mathrm{AGs}$ in $\operatorname{DexC}_{6}-\tau$ aggregates because of the relatively high stabilizer concentration. Increasing $M_{\mathrm{tot}}$ (keeping $W_{\mathrm{AG}}^{i}$ unchanged) allowed a significant increase in the encapsulation efficiency. 
Tables $5 \& 6$

At drug loading below the critical values, all suspensions of AG-loaded nanoparticles were stable after centrifugation and when the ionic strength was increased up to $1 \mathrm{M} \mathrm{NaCl}$. A TEM micrograph of NG2 nanoparticles after centrifugation and re-dispersion confirmed that the nanoparticles were perfectly spherical, non-aggregated, and exhibited a quasi monomodal size distribution, in accordance with data from laser granulometry (Fig. 9).

Fig. 9

\subsubsection{Encapsulation into microparticles (ranges 2 and 3)}

For both processes, particle characteristics were similar to those of PLA particles prepared without AGs, however very different encapsulation efficiencies were obtained depending on the process used. These differences were related to the partition of AGs between the organic and aqueous phases. Low encapsulation efficiency (12.4\%) was obtained in the case of OG-loaded particles produced by MFFD, which was attributed to the low ratio of the organic phase flow rate to that of the aqueous phase (1:20), together with the low concentration of PLA+OG in the organic phase $(10 \mathrm{mg} / \mathrm{mL})$. Conversely, higher encapsulation efficiency (more than 90\%) was reached for particles prepared by magnetic stirring (Table 7), because of the higher volume ratio of organic to aqueous phase (1:2), together with the higher concentration of PLA+AG $(50 \mathrm{mg} / \mathrm{mL})$.

Table 7

\subsubsection{In vitro release kinetics}

The in vitro release of OG and NG was studied with nanoparticles (range 1) and microparticles (range 3). It has previously been shown that the nature of the cryoprotectant used during the freeze-drying step could slightly modify the kinetics of release (Jeong et al., 2005). In that work, all in vitro release experiments were carried out using freshly prepared samples of nano- and microparticles. Some preliminary release experiments were carried out with freeze-dried and reconstituted samples of nanoparticles, which revealed comparable kinetics to those observed with freshly prepared samples. However, further investigation is required to draw a precise conclusion. Therefore, in this work, we focused on the kinetics of AG release from freshly prepared nano- and microparticles.

In deionized water AG-loaded nanoparticles exhibited a progressive release of OG and NG with no burst effect (Fig. 10). In previous work, we showed that the kinetics of release from nanoparticles could be satisfactorily fitted assuming that the limiting step was the diffusion of AGs within the solid PLA core, in perfect sink conditions, and with no swelling of the PLA core (Chebil et al., 2018b). We showed that the diffusion coefficients estimated with the previous model were in agreement with literature data and exhibited a limited dependence on drug loading, which was consistent with the idea of a perfect molecular 
dissolution of AGs in a PLA matrix. The diffusion coefficients found for NG were between 5 and 10 times lower than those found for OG, which was attributed to the lower compatibility of NG with PLA. For the nanoparticles, approximately $90 \%$ of the initial OG load was released after $100 \mathrm{~h}$, while $~ 60 \%$ of the initial NG load was released over the same period.

Fig. 10

When AG-loaded microparticles (range 3) were dispersed in deionized water, no release was detected after 20 days. Taking into account the size of the microparticles and assuming that, similarly to nanoparticles, the release was limited by diffusion within the solid core, this result appeared fully consistent. It has been shown that $\mathrm{pH}$ can significantly influence the kinetics of drug release from a PLA matrix as a result of: variation of drug solubility and swelling and hydrolytic degradation of the PLA matrix (Grandfils, Flandroy, \& Jerome, 1996; Proikakis, Mamouzelos, Tarantili, \& Andreopoulos, 2006; Proikakis, Tarantili, \& Andreopoulos, 2006). As a consequence, AG release from microparticles was carried out in a Tris/ $\mathrm{HCl}$ buffer, $\mathrm{pH} 8.5$. After 4 months, approximately $65 \%$ of the initial OG load, and $40 \%$ of the initial NG load, had been released (Fig. 11). Similarly to nanoparticles, no significant burst effect was detected and OG was released faster than NG. It is clear that AG diffusion within the solid PLA matrix is not the limiting step of AG release. Monitoring the weight-average molar mass of the PLA matrix in microparticles over time revealed that limited polymer degradation took place over the period of AG release (Fig. 12). Because of the slightly lower molar masses of PLA after 20 days or more in the Tris/HCl buffer $\mathrm{pH} 8.5$, it seemed that hydrolytic degradation of PLA was faster in the presence of OG than in the presence of NG. Thus, the decrease in the weight-average molar mass of PLA was more pronounced in the case of OG-loaded microparticles. In addition, the swelling of microparticles was shown by optical microscopy, both initially and after 3 months, with no evidence of particle aggregation (Fig. 13). Indeed, the average particle diameter of OG1-m and NG1-m microparticles increased from 469 to $650 \mu \mathrm{m}$, and from 417 to $480 \mu \mathrm{m}$, respectively. The corresponding estimated degrees of swelling were 166\% for OG1-m particles and 53\% for NG1-m particles. The lower degree of swelling as well as the reduced hydrolytic degradation of PLA observed for PLA+NG particles as compared with PLA+OG particles, was attributed to the higher hydrophobicity of NG compared with OG and thus to the lower hydrophilicity of the core material of the microparticles. Nevertheless, further studies are necessary to support this assumption. The equation proposed by Gallagher and Corrigan was found to conveniently fit experimental results for both OG and NG (Gallagher \& Corrigan, 2000) (Fig. 11). However, considering both the fact that this equation involved 4 adjustable parameters, and the experimental accuracy, we prefer not to discuss the found values further. More experimental results would be necessary for a reliable discussion of the fitted parameters.

Figs. 11-13

We concluded that AG release from microparticles prepared by mechanical stirring was controlled by swelling and hydrolytic degradation of the PLA matrix.

\section{Conclusions}


Suspensions of PLA particles stabilized by amphiphilic polysaccharides derived from dextran were prepared by $\mathrm{O} / \mathrm{W}$ emulsification based on different lab-scale procedures (ultrasonic, microfluidic, and mechanical stirring). This allowed suspensions of particles with different size ranges, exhibiting monomodal, narrow distributions to be obtained. While nanoparticle suspensions required the addition of a cryoprotectant (trehalose) before freeze-drying to prevent aggregation, suspensions of microparticles could be freeze-dried and reconstituted without any cryoprotectant. The encapsulation of antioxidants-alkyl esters of gallic acid-was designed and particularly adapted for octyl gallate and nonyl gallate. Encapsulation efficiency was mainly dependent on the partition coefficient of gallate between the organic dispersed phase and the continuous aqueous phase. The presence of amphiphilic polysaccharide at the surface of particles was confirmed and provided convenient colloidal stability during washing steps for the removal of excess compounds (e.g., stabilizers and antioxidants).

For PLA nanoparticles, OG and NG release was mainly controlled by the rate of diffusion of the dispersed AG. Octyl gallate was completely released from nanoparticles particles over 5 days under sink conditions. The diffusion of nonyl gallate was slower. Finally, it was demonstrated that the diffusion of gallates from microparticles was mainly governed by the swelling behavior and hydrolytic degradation of the PLA matrix as a function of $\mathrm{pH}$. For both OG and NG, the release from the microparticles extended over several weeks.

Ongoing work is focusing on the scale of the production of each type of particle and the release of OG and NG from microparticles prepared using a microfluidic system. In addition, taking into account the different release kinetics resulting from the range of particle diameters, we are examining the possible control of overall release kinetics on the basis of mixtures of particles of different size ranges.

\section{Acknowledgments}

The authors gratefully acknowledge the financial support of Région Lorraine and the European Union (FEDER) for the BioCapTech project ( $\mathrm{PhD}$ of AC). Loïc Chomel de Varagnes and Jean-Claude Pihan (BioCapTech Company) are acknowledged for many fruitful discussions.

\section{References}

Ansary, R. H., Awang, M. B., \& Rahman, M. M. (2014). Biodegradable poly(D,L-lactic-co-glycolic acid)based micro/nanoparticles for sustained release of protein drugs-A review. Tropical Journal of Pharmaceutical Research, 13, 1179-1190.

Aumelas, A., Serrero, A., Durand, A., Dellacherie, E., \& Leonard, M. (2007). Nanoparticles of hydrophobically modified dextrans as potential drug-carrier systems. Colloids and Surfaces B: Biointerfaces, 59, 74-80. 
Bauer, W. A. C., Fischlechner, M., Abell, C., \& Huck, W. T. S. (2010). Hydrophilic PDMS microchannels for high-throughput formation of oil-in-water microdroplets and water-in-oil-in-water double emulsions. Lab on a Chip, 10, 1814-1819.

Bowen, P. (2002). Particle size distribution measurement from millimeters to nanometers and from rods to platelets. Journal of Dispersion Science and Technology, 23, 631-662.

Chebil, A., Funfschilling, D., Léonard, M., Six, J.-L., Nouvel, C., \& Durand A. (2018a). Amphiphilic polysaccharides acting both as stabilizers and surface modifiers during emulsification in microfluidic flow-focusing junction. ACS Applied Bio Materials, 1, 879-887.

Chebil, A., Léonard, M., Six, J.L., Nouvel, C., \& Durand, A. (2018b). Nanoparticulate delivery systems for alkyl gallates: Influence of the elaboration process on particle characteristics, drug encapsulation and in-vitro release. Colloids and Surfaces B: Biointerfaces, 162, 351-361.

Chen, P. W., Erb, R. M., \& Studart, A. R. (2012). Designer polymer-based microcapsules made using microfluidics. Langmuir, 28, 144-152.

Chittasupho, C., Thongnopkoon, T., \& Kewsuwan, P. (2016). Surface modification of poly(D,L-lactic-coglycolic acid) nanoparticles using sodium carboxymethyl cellulose as colloidal stabilizer. Current Drug Delivery, 13, 95-104.

Covis, R., Baravian, C., Marie, E., \& Durand, A. (2015). Kinetics of formation of polysaccharide-covered micrometric oil droplets under mechanical agitation. Colloids and Surfaces A: Physicochemical and Engineering Aspects, 466, 92-99.

Desgouilles, S., Vaulthier, C., Bazile, D., Vacus, J., Grossiord, J. L., \& Veillard, M., et al. (2003). The design of nanoparticles obtained by solvent evaporation: a comprehensive study. Langmuir, 19, 95049510.

Dunne, M., Bibby, D. C., Jones, J. C., \& Cudmore, S. (2003). Encapsulation of protamine sulphate compacted DNA in polylactide and polylactide-co-glycolide microparticles. Journal of Controlled Release , 92, 209-219.

Durand, A., Marie, E., Rotureau, E., Léonard, M., \& Dellacherie, E. (2004). Amphiphilic polysaccharides: Useful tools for the preparation of nanoparticles with controlled surface characteristics. Langmuir, 20, 6956-6963.

Fonte, P., Soares, S., Costa, A., Andrade, J. C., Seabra, V., \& Reis, S., et al. (2012). Effect of cryoprotectant on the porosity and stability of insulin-loaded PLGA nanoparticles after freeze-drying. Biomatter, 2, 329-339. 
Fournier, C., Léonard, M., Dellacherie, E., Chikhi, M., Hommel, H., \& Legrand, A. P. (1998). EPR spectroscopy analysis of hydrophobically modified dextran-coated polystyrene. Journal of Colloid and Interface Science, 198(1), 27-33.

Fu, T., Ma, Y., Funfschilling, D., Zhu, C., \& Li, H. Z. (2012). Breakup dynamics of slender bubbles in non-newtonian fluids in microfluidic flow-focusing devices. AIChE Journal, 58, 3560-3567.

Fuentes, I., Blanco-Fernandez, B., Alvarado, N., Leiva, A., Radić, D., \& Alvarez-Lorenzo, C., et al. (2016). Encapsulation of antioxidant gallate derivatives in biocompatible poly ( $\varepsilon$-caprolactone)-b-pluronic-bpoly (E-caprolactone) micelles . Langmuir, 32, 3331-3339.

Gallagher, K. M., \& Corrigan, O. I. (2000). Mechanistic aspects of the release of levamisole hydrochloride from biodegradable polymers. Journal of Controlled Release, 69, 261-272.

Garlotta, D. (2001). A literature review of poly (lactic acid). Journal of Polymers and the Environment, $9(2), 63-84$.

Gaumet, M., Vargas, A., Gurny, R., \& Delie, F. (2008). Nanoparticles for drug delivery: The need for precision in reporting particle size parameters. European Journal of Pharmaceutics and Biopharmaceutics, 69, 1-9.

Gavory, C., Durand, A., Six, J.L., Nouvel, C., Marie, E., \& Leonard, M. (2011). Polysaccharide-covered nanoparticles prepared by nanoprecipitation. Carbohydrate Polymers, 84, 133-140.

Graessley, W. W. (1980). Polymer chain dimensions and the dependence of viscoelastic properties on concentration, molecular weight and solvent power. Polymer, 21, 258-262.

Grandfils, C., Flandroy, P., \& Jerome, R. (1996). Control of the biodegradation rate of poly (DL-lactide) microparticles intended as chemoembolization materials. Journal of Controlled Release, 38, 109-122.

Guo, Y., Wang, X., Shu, X., Shen, Z., \& Sun, R. C. (2012). Self-assembly and paclitaxel loading capacity of cellulose-graft-poly (lactide) nanomicelles. Journal of Agricultural and Food Chemistry, 60, 39003908.

Heins, A., Garamus, V. M., Steffen, B., Stöckmann, H., \& Schwarz, K. (2006). Impact of phenolic antioxidants on structural properties of micellar solutions. Food Biophysics, 1, 189-201.

Huang, S., Wan, Y., Wang, Z., \& Wu, J. (2013). Folate-conjugated chitosan-polylactide nanoparticles for enhanced intracellular uptake of anticancer drug. Journal of Nanoparticle Research, 15, 2096. 
Jeannot, V., Mazzaferro, S., Lavaud, J., Vanwonterghem, L., Henry, M., \& Arboléas, M., et al. (2013). Targeting CD44 receptor-positive lung tumors using polysaccharide-based nanocarriers: Influence of nanoparticle size and administration route. Nanomedicine: Nanotechnology, Biology and Medicine, $12,921-932$.

Jeong, Y. I., Kim, D. H., Chung, C. W., Yoo, J. J., Choi, K. H., \& Kim, C. H., et al. (2012). Self-assembled nanoparticles of hyaluronic acid/poly(dl-lactide-co-glycolide) block copolymer. Colloids and Surfaces B: Biointerfaces, 90, 28-35.

Jeong, Y. I., Na, H. S., Oh, J. S., Choi, K. C., Song, C. E., \& Lee, H. C. (2006). Adriamycin release from self-assembling nanospheres of poly(dl-lactide-co-glycolide)-grafted pullulan. International Journal of Pharmaceutics, 322, 154-160.

Jeong, Y. I., Shim, Y. H., Kim, C., Lim, G. T., Choi, K. C., \& Yoon, C. (2005). Effect of cryoprotectants on the reconstitution of surfactant-free nanoparticles of poly(DL-lactide-co-glycolide). Journal of Microencapsulation, 22, 593-601.

Jiang, G., Tang, S., Chen, X., \& Ding, F. (2014). Enhancing the receptor-mediated cell uptake of PLGA nanoparticle for targeted drug delivery by incorporation chitosan onto the particle surface. Journal of Nanoparticle Research, 16, 2453.

Keohane, K., Brennan, D., Galvin, P., \& Griffin, B. T. (2014). Silicon microfluidic flow focusing devices for the production of size-controlled PLGA based drug loaded microparticles. International Journal of Pharmaceutics, 467, 60-69.

Khan, I. U., Serra, C. A., Anton, N., \& Vandamme, T. (2013). Continuous-flow encapsulation of ketoprofen in copolymer microbeads via co-axial microfluidic device: Influence of operating and material parameters on drug carrier properties. International Journal of Pharmaceutics, 441, 809-817.

Kim, J. H., Jeon, T. Y., Choi, T. M., Shim, T. S., Kim, S. H., \& Yang, S. M. (2014). Droplet microfluidics for producing functional microparticles. Langmuir, 30, 1473-1488.

Kumari, A., Yadav, S.K., \& Yadav, S.C. (2010). Biodegradable polymeric nanoparticles based drug delivery systems. Colloids and Surfaces B: Biointerfaces, 75, 1-18.

Lacatelly, C., Filippin-Monteiro, F. B. \& Creczynski-Pasa, T. B. (2013). Alkyl esters of gallic acid as anticancer agent: A review. European Journal of Medicinal Chemistry, 60, 233-239.

Laroui, H., Grossin, L., Léonard, M., Stoltz, J. F., Gillet, P., \& Netter, P., et al. (2007). Hyaluronatecovered nanoparticles for the therapeutic targeting of cartilage. Biomacromolecules, 8, 3879-3885. 
Laville, M., Babin, J., Londono, I., Legros, M., Nouvel, C., \& Durand, A., et al. (2013). Polysaccharidecovered nanoparticles with improved shell stability using synthetic strategies based on clickchemistry. Carbohydrate Polymers, 93, 537-546.

Lemarchand, C., Gref, R., \& Couvreur, P. (2004). Polysaccharide- decorated nanoparticles. European Journal of Pharmaceutics and Biopharmaceutics, 58, 327-341.

Ma, W. J., Yuan, X. B., Kang, C. S., Su, T., Yuan, X. Y., \& Pu, P. Y., et al. (2008). Evaluation of blood circulation of polysaccharide surface-decorated PLA nanoparticles. Carbohydrate Polymers, 72, 7581.

Maji, D., Lahiri, S. K., \& Das, S. (2012). Study of hydrophilicity and stability of chemically modified PDMS surface using piranha and KOH solution. Surface and Interface Analysis, 44, 62-69.

Maldonado, O. S., Lucas, R., Comelles, F., Gonzalez, M. J., Parra, J. L., \& Medina, I., et al. (2011). Synthesis and characterization of phenolic antioxidants with surfactant properties: Glucosyl- and glucuronosyl alkyl gallates. Tetrahedron, 67, 7268-7279.

Martin-Banderas, L., Flores-Mosquera, L. M., Riesco-Chueca, P., Rodriguez-Gil, A., Cebolla, Á., \& Chávez, S., et al. (2005). Flow focusing: A versatile technology to produce size-controlled and specific-morphology microparticles. Small, 1, 688-692.

McDonald, J. C., Duffy, D. C., Anderson, J. R., Chiu, D. T., Wu, H., \& Schueller, O. J., et al. (2000). Fabrication of microfluidic systems in poly(dimethylsiloxane). Electrophoresis: An International Journal. 21(1), 27-40.

Nottelet, B., Darcos, V., \& Coudane, J. (2015). Aliphatic polyesters for medical imaging and theranostic applications. European Journal of Pharmaceutics and Biopharmaceutics B, 97, 350-370.

Nouvel, C., Dubois, P., Dellacherie, E., \& Six, J.L. (2004). Controlled synthesis of amphiphilic biodegradable polylactide-grafted dextran copolymers. Journal of Polymer Science Part A: Polymer Chemistry, 42, 2577-2588.

Nouvel, C., Raynaud, J., Marie, E., Dellacherie, E., Six, J. L., \& Durand, A. (2009). Biodegradable nanoparticles made from polylactide-grafted dextran copolymers. Journal of Colloid and Interface Science, 330, 337-343.

Österberg, E., Bergstrom, K., Holmberg, K., Schuman, T. P., Riggs, J. A., \& Burns, N. L., et al. (1995). Protein-rejecting ability of surface-bound dextran in end-on and side-on configurations-Comparison to PEG. Journal of Biomedical Materials Research, 29, 741-747. 
Peltonen, L. \& Hirvonen, J. (2008). Physical characterization of nano and microparticles. Current Nanoscience, 4, 101-107.

Pessi, J., Santos, H. A., Miroshnyk, I., Yliruusi, J., \& Mirza, S. (2014). Microfluidics-assisted engineering of polymeric microcapsules with high encapsulation efficiency for protein drug delivery. International Journal of Pharmaceutics, 472, 82-87.

Pitarresi, G., Palumbo, F. S., Fiorica, C., Calascibetta, F., Di Stefano, M., \& Giammona, G. (2013). Injectable in situ forming microgels of hyaluronic acid-g-polylactic acid for methylprednisolone release. European Polymer Journal, 49, 718-725.

Poltorak, K., Durand, A., Léonard, M., Six, J.L., \& Nouvel, C. (2015). Interfacial click chemistry for improving both dextran shell density and stability of biocompatible nanocapsules. Colloids and Surfaces A: Physicochemical and Engineering Aspects, 483, 8-17.

Proikakis, C. S., Mamouzelos, N. J., Tarantili, P. A., \& Andreopoulos, A. G. (2006). Swelling and hydrolytic degradation of poly(D,L-lactic acid) in aqueous solutions. Polymer Degradation and Stability, 91, 614-619.

Proikakis, C. S., Tarantili, P. A., \& Andreopoulos, A. G. (2006). The role of polymer/drug interactions on the sustained release from poly(DL-lactic acid) tablets. European Polymer Journal, 42, 3269-3276.

Rizkalla, N., Range, C., Lacasse, F. X., \& Hildgen, P. (2006). Effect of various formulation parameters on the properties of polymeric nanoparticles prepared by multiple emulsion method. Journal of Microencapsulation, 23(1), 39-57.

Rosso, R., Vieira, T. O., Leal, P. C., Nunes, R. J., Yunes, R. A., \& Creczynski-Pasa. (2006). Relationship between the lipophilicity of gallic acid n-alquil esters' derivatives and both myeloperoxidase activity and HOCl scavenging. Bioorganic \& Medicinal Chemistry, 14, 6406-6413.

Rotureau, E., Chassenieux, C., Dellacherie, E., \& Durand, A. (2005). Neutral polymeric surfactants derived from dextran: a study of their aqueous solution behavior. Macromolecular Chemistry and Physics, 206, 2038-2046.

Rotureau, E., Marie, E., Léonard, M., Dellacherie, E., Camesano, T. A., \& Durand, A. (2006). From polymeric surfactants to colloidal systems (2): Preparation of colloidal dispersions. Colloids and Surfaces A: Physicochemical and Engineering Aspects, 288, 62-70.

Rouzes, C., Léonard, M., Durand, A., \& Dellacherie, E. (2003). Influence of polymeric surfactants on the properties of drug-loaded PLA nanospheres. Colloids and Surfaces B: Biointerfaces, 32, 125-135. 
Saez, A., Guzman, M., Molpeceres, J., \& Aberturas, M. R. (2000). Freeze-drying of polycaprolactone and poly (D, L-lactic glycolic) nanoparticles induce minor particle size changes affecting the oral pharmacokinetics of loaded drugs. European Journal of Pharmaceutics and Biopharmaceutics, 50, 379-387.

Sansdrap, P., \& Moës, A. J. (1993). Influence of manufacturing parameters on the size characteristics and the release profiles of nifedipine from poly(D,L-lactide-co-glycolide) microspheres. International Journal of Pharmaceutics, 98, 157-164.

Seemann, R., Brinkmann, M., Pfohl, T., \& Herminghaus, S. (2012). Droplet based microfluidics. Reports on Progress in Physics, 75(1), 016601.

Sergediene, E., Jönsson, K., Szymusiak, H., Tyrakowska, B., Rietjens, I. M., \& Narimantas, Č. (1999). Prooxidant toxicity of polyphenolic antioxidants to HL-60 cells: Description of quantitative structureactivity relationships. FEBS Letters, 462, 392-396.

Serra, C. A., Cortese, B., Khan, I. U., Anton, N., de Croon, M. H., \& Hessel, V., et al. (2013). Coupling microreaction technologies, polymer chemistry, and processing to produce polymeric micro and nanoparticles with controlled size, morphology, and composition. Macromolecular Reaction Engineering, 7, 414-439.

Velasco, J., Holgado, F., Dobarganes, C., \& Marquez-Ruiz, G. (2009). Antioxidant activity of added phenolic compounds in freeze-dried microencapsulated sunflower oil. Journal of the American Oil Chemists' Society, 86, 445-452.

Wischke, C., \& Schwendeman, S. P. (2008). Principles of encapsulating hydrophobic drugs in PLA/PLGA microparticles. International Journal of Pharmaceutics, 364, 298-327.

Yadav, A. K., Mishra, P., Mishra, A. K., Mishra, P., Jain, S., \& Agrawal, G. P. (2007). Development and characterization of hyaluronic acid-anchored PLGA nanoparticulate carriers of doxorubicin. Nanomedicine, 3, 246-257.

Zille, H., Paquet, J., Henrionnet, C., Scala-Bertola, J., Jain, S., \& Agrawal, G. P., et al. (2010). Evaluation of intra-articular delivery of Hyaluronic Acid functionalized biopolymeric nanoparticles in healthy rats knees. Bio-Medical Materials and Engineering, 20, 235-242. 


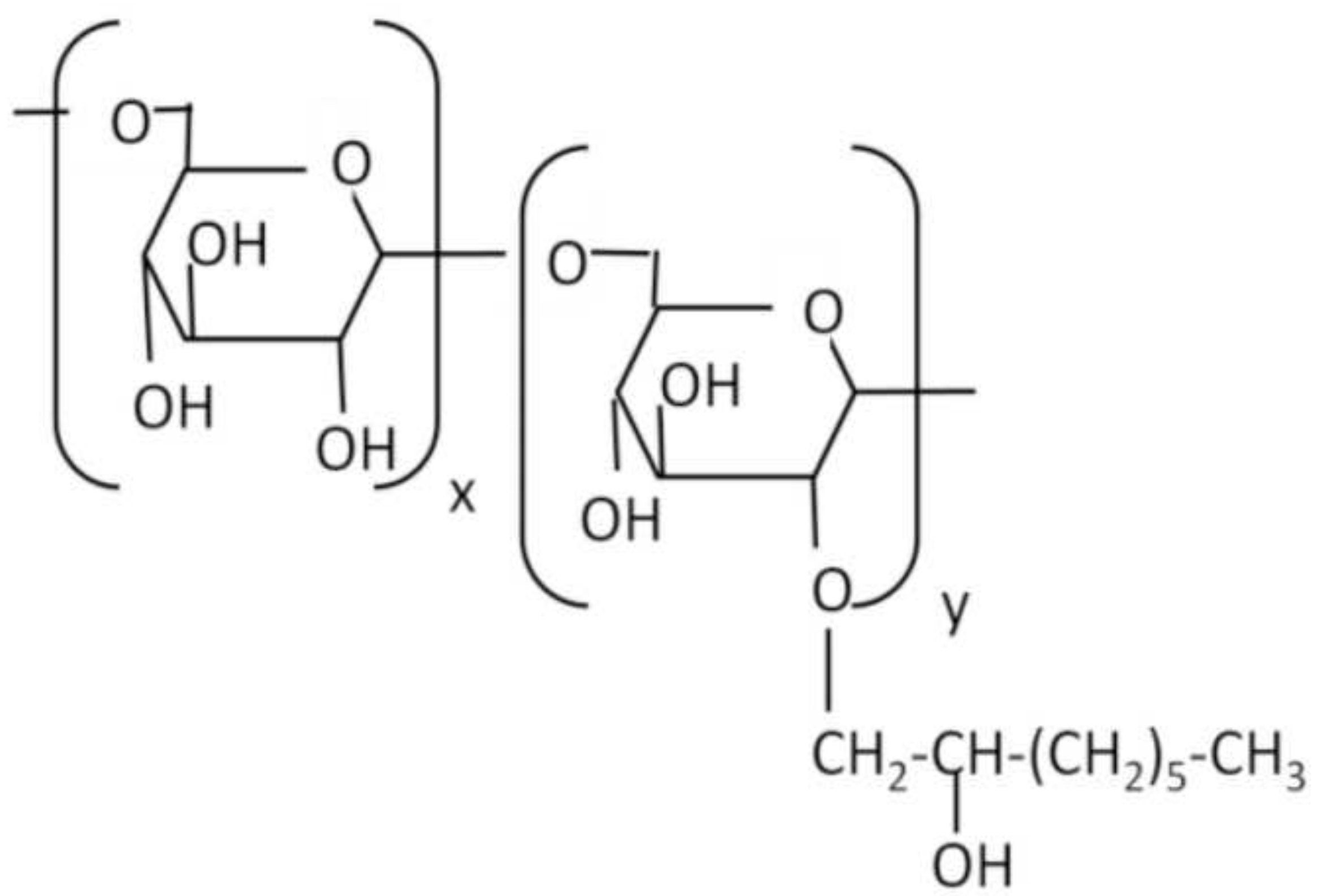




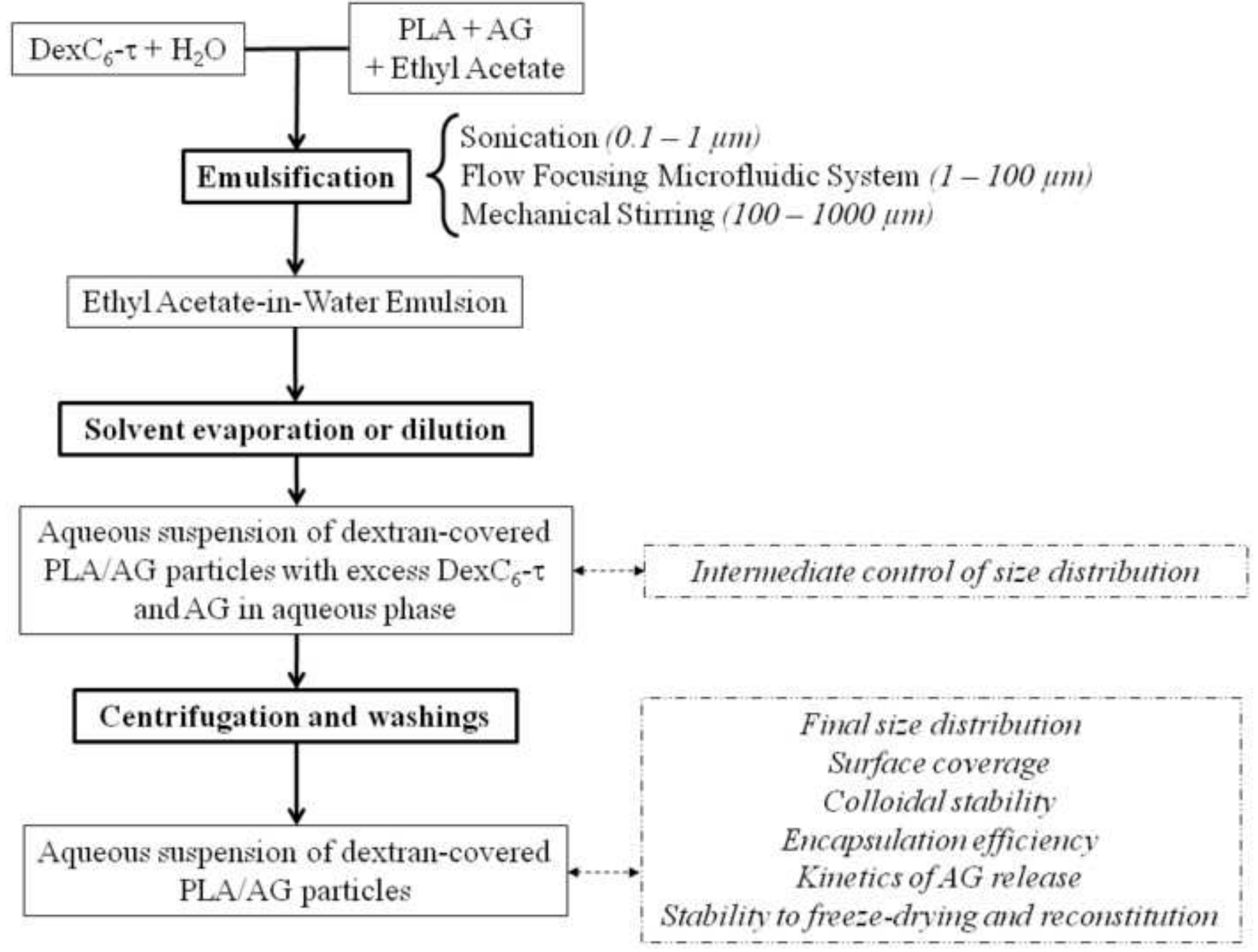




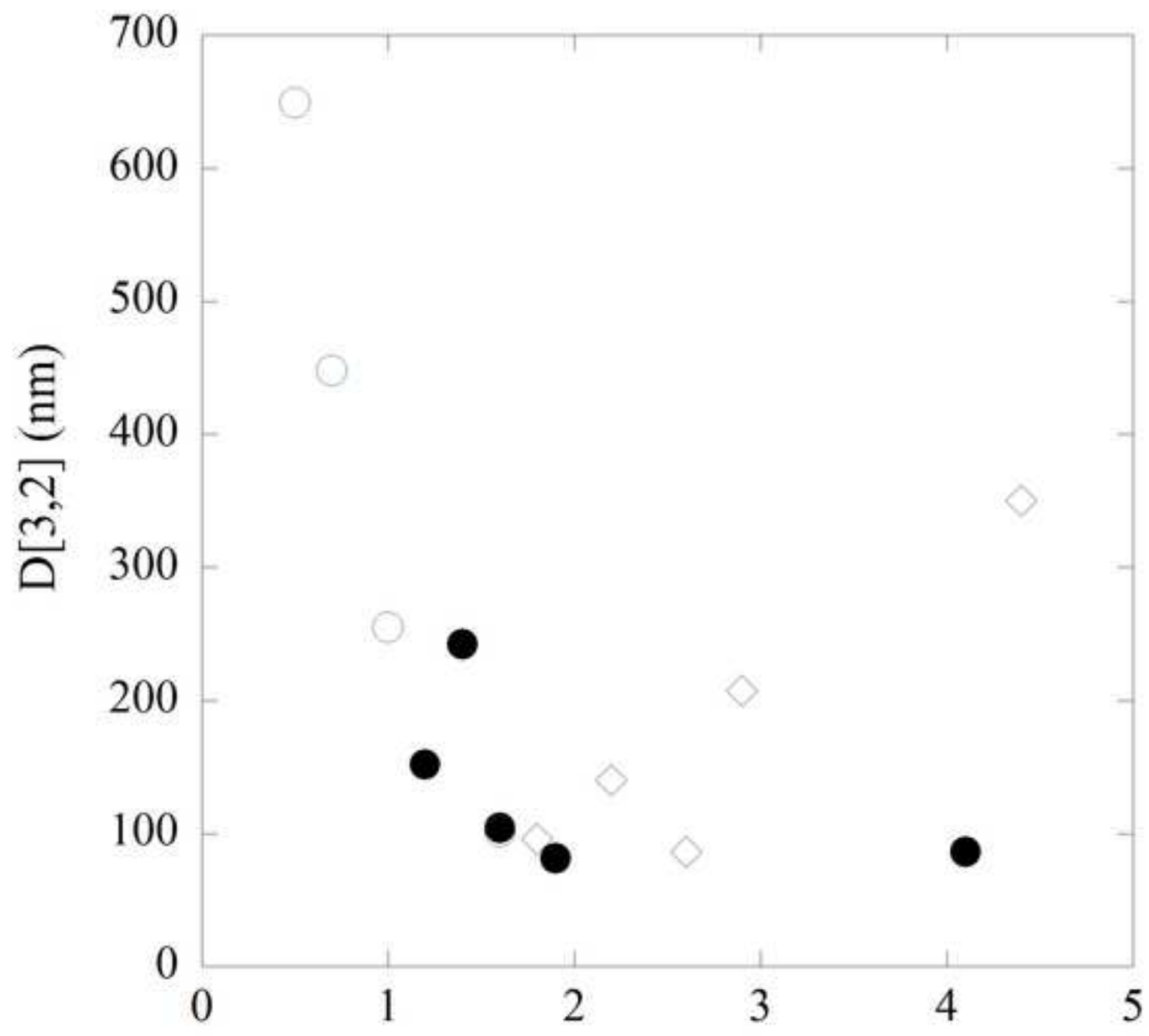

Maximal possible surface coverage of oil droplets $\left(\mathrm{mg} / \mathrm{m}^{2}\right)$ 


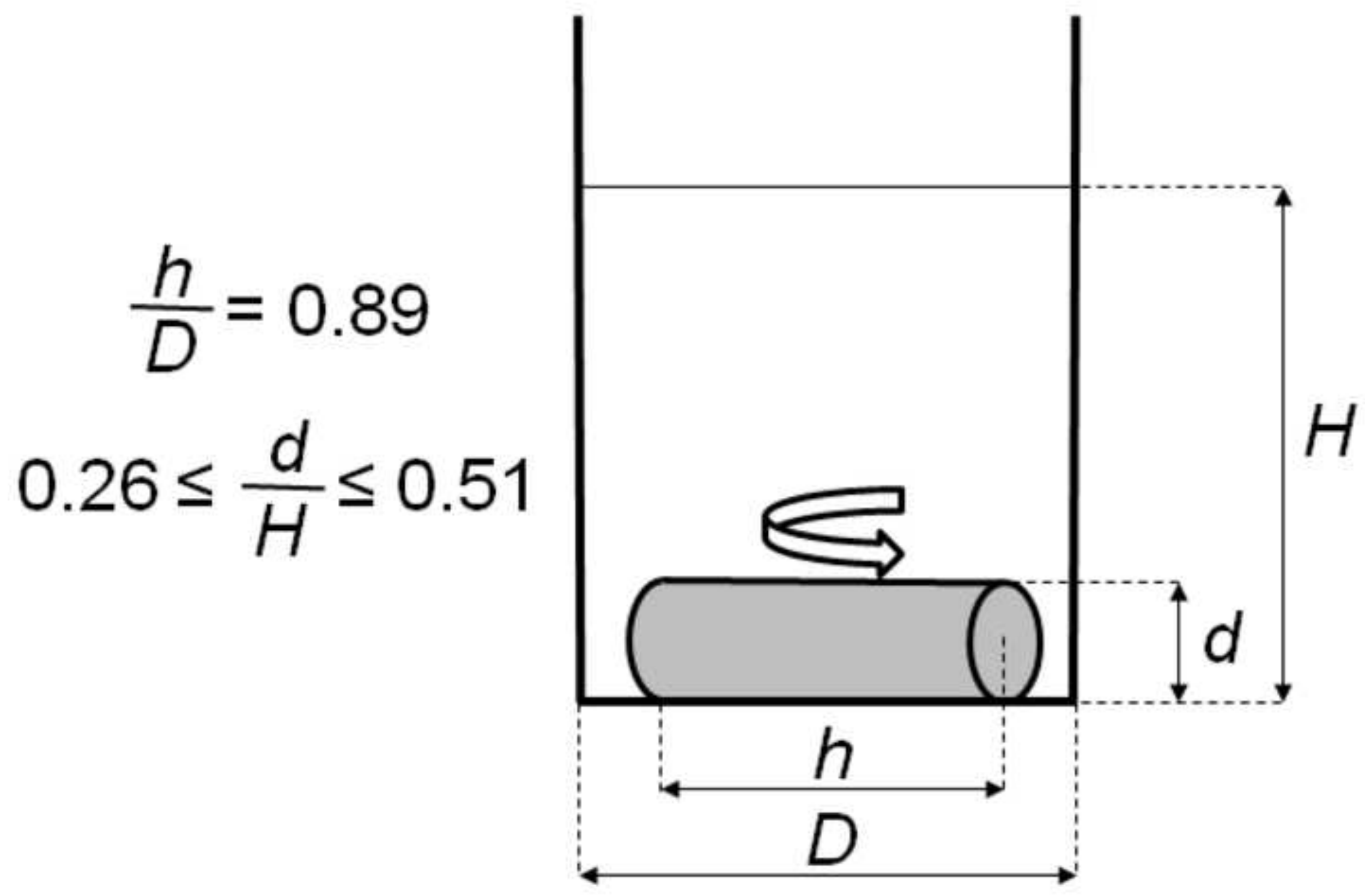


Click here to download high resolution image
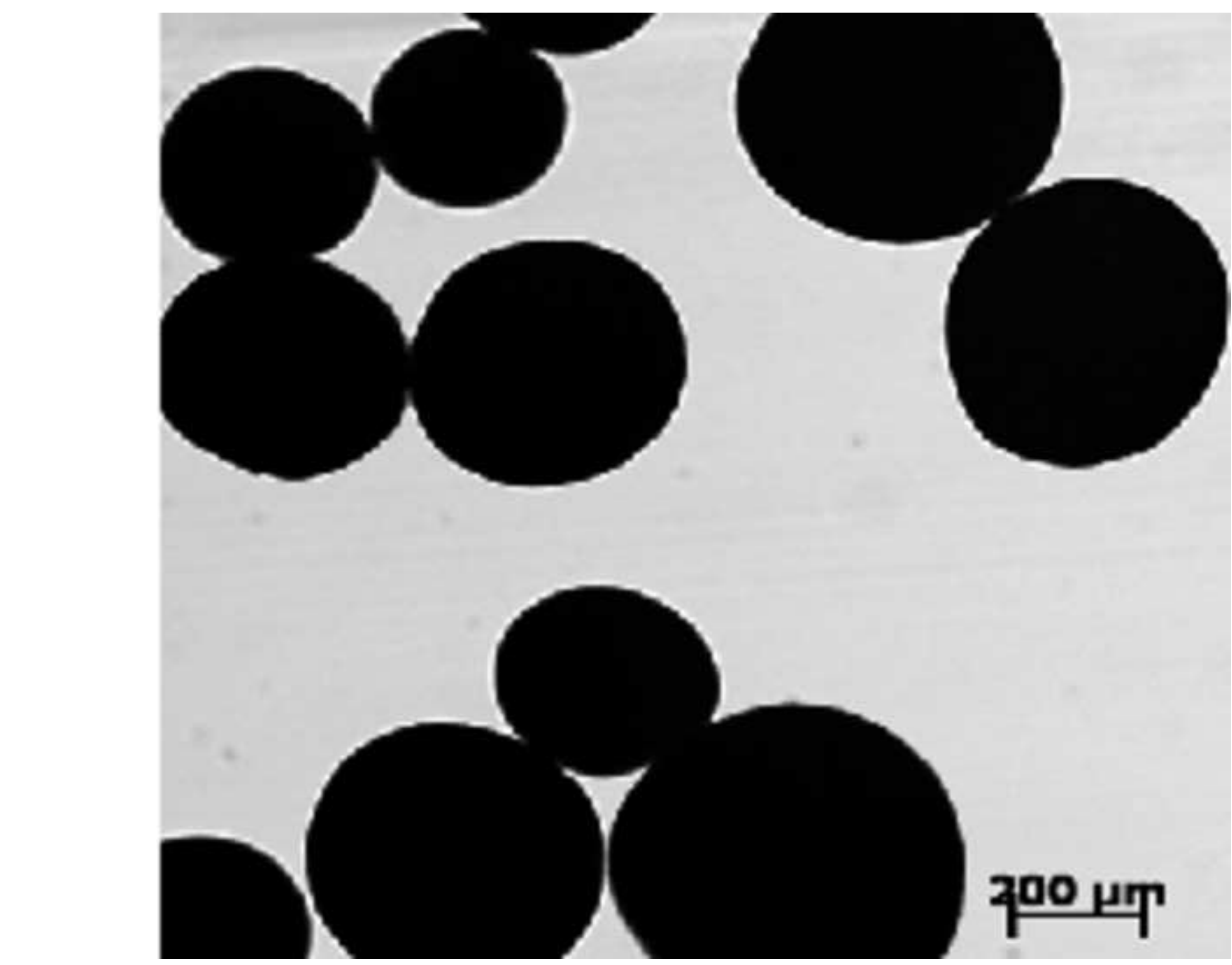

\section{4}




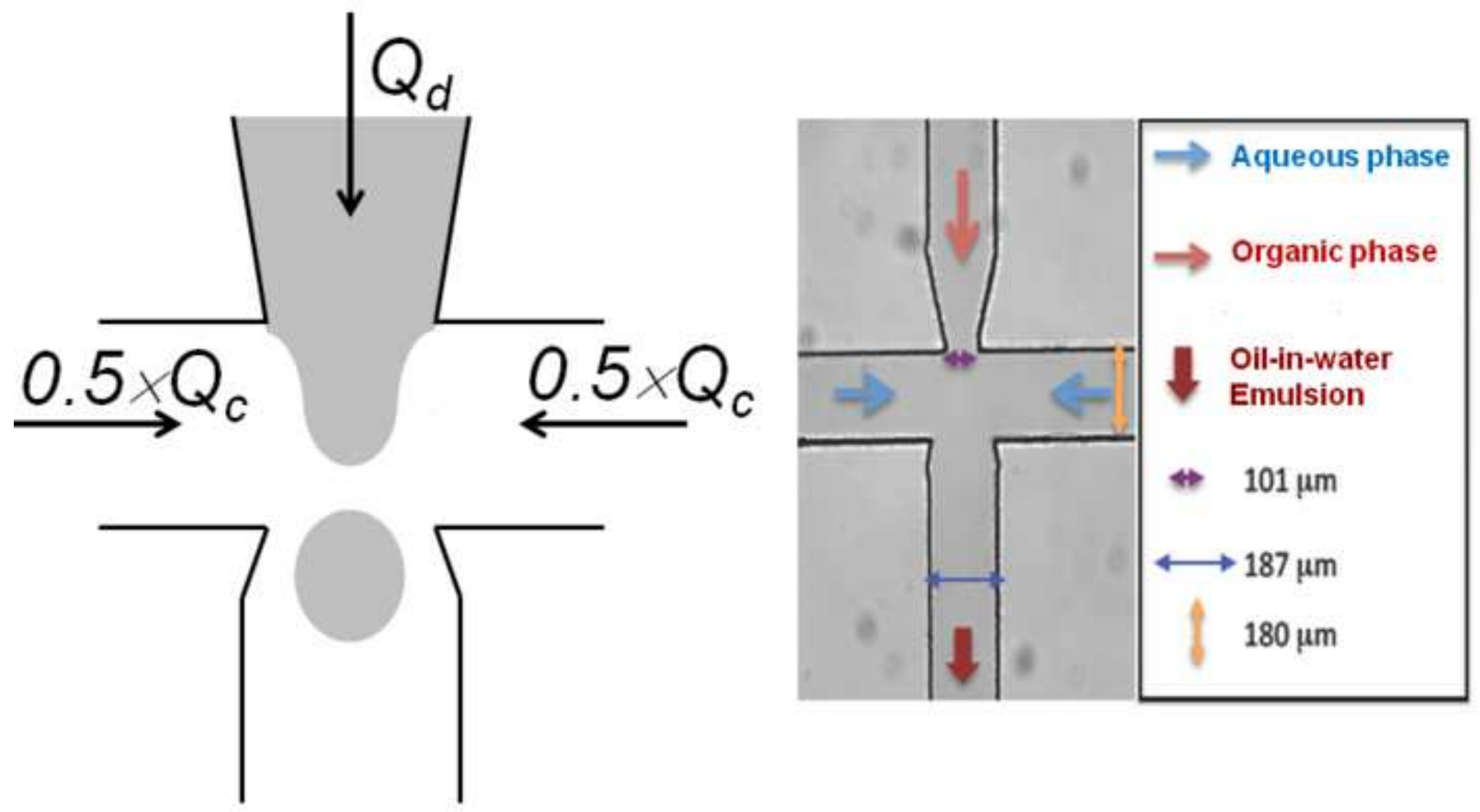


Click here to download high resolution image

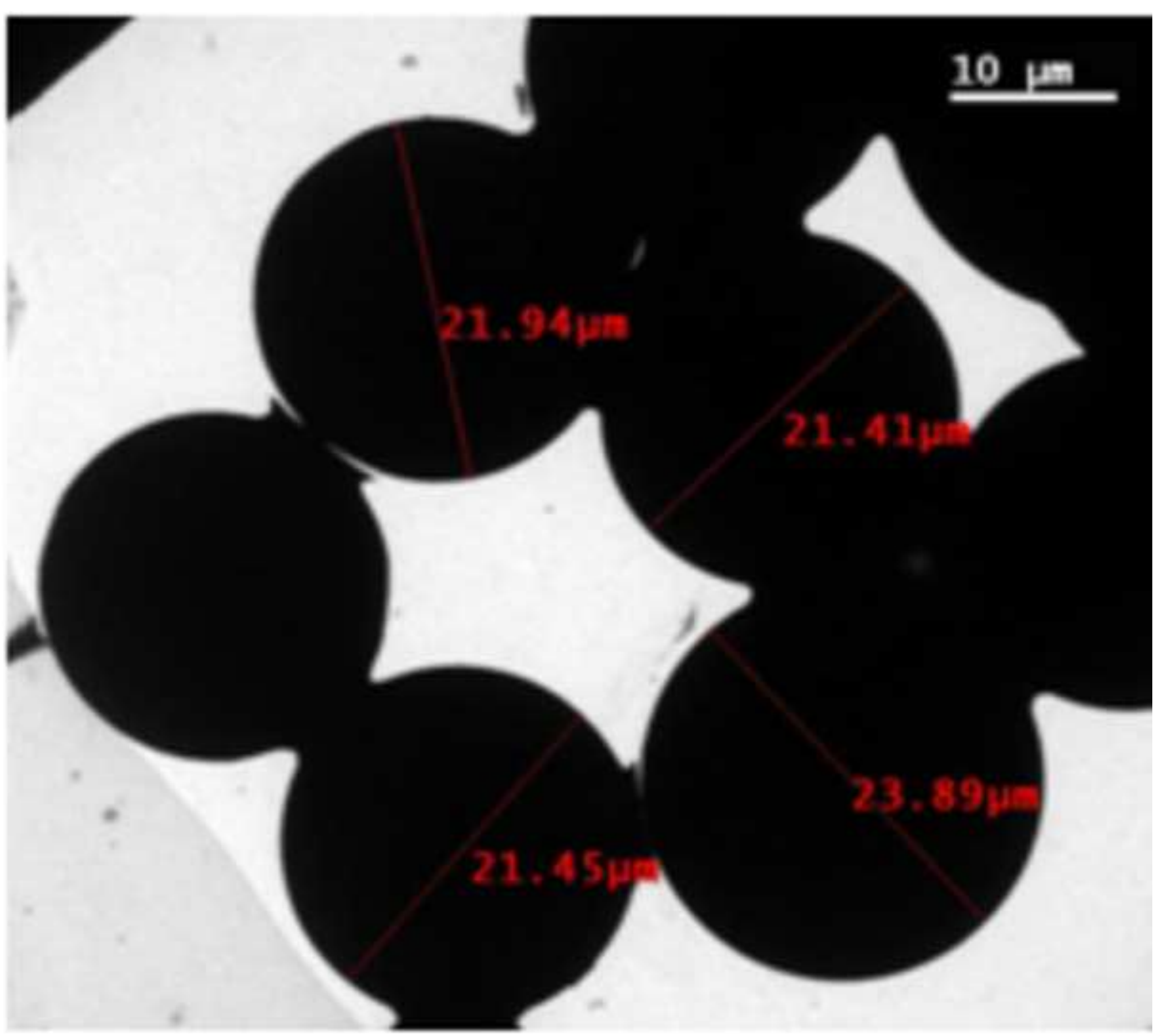


Click here to download high resolution image

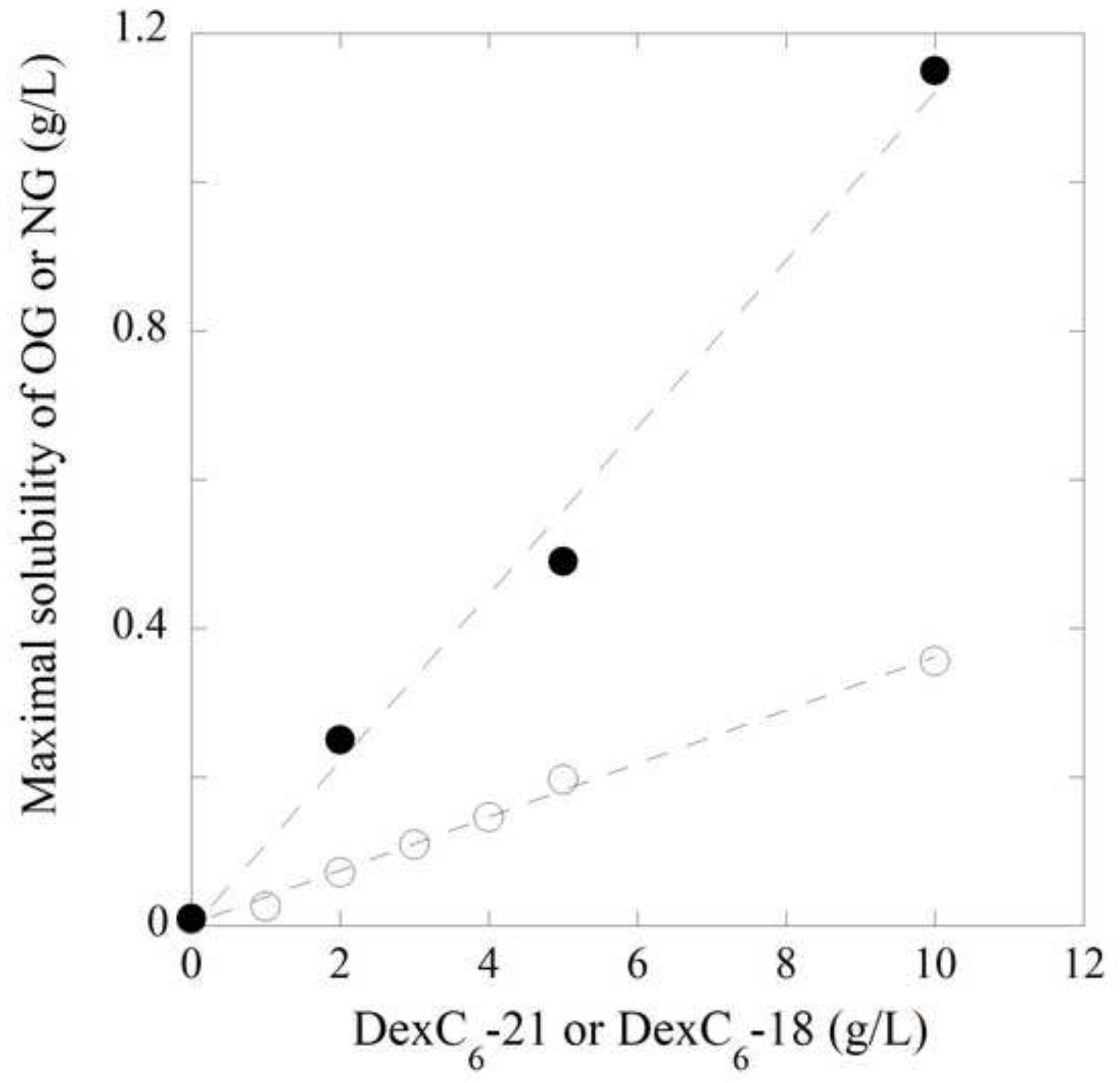




\section{Click here to download high resolution image}

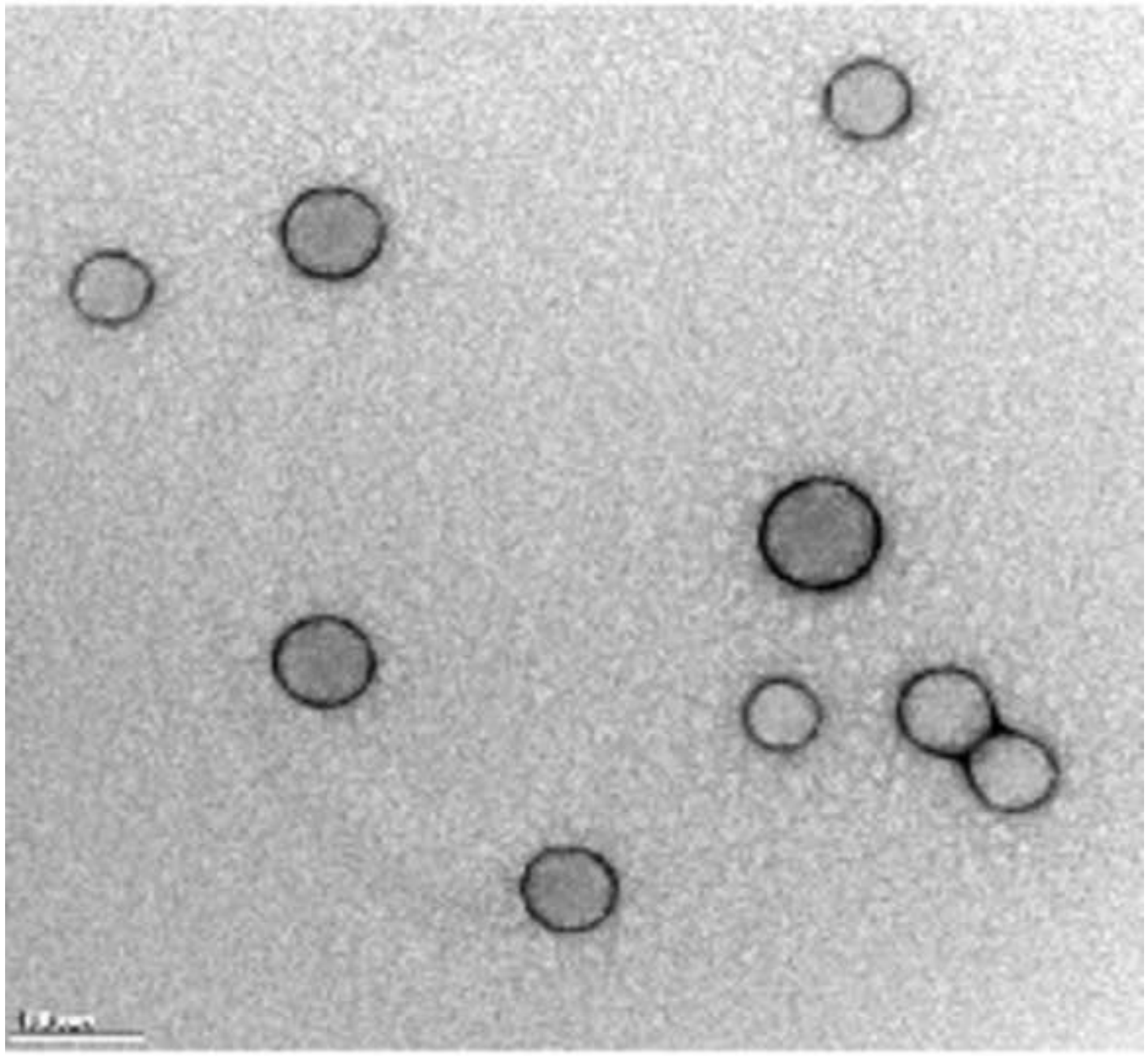




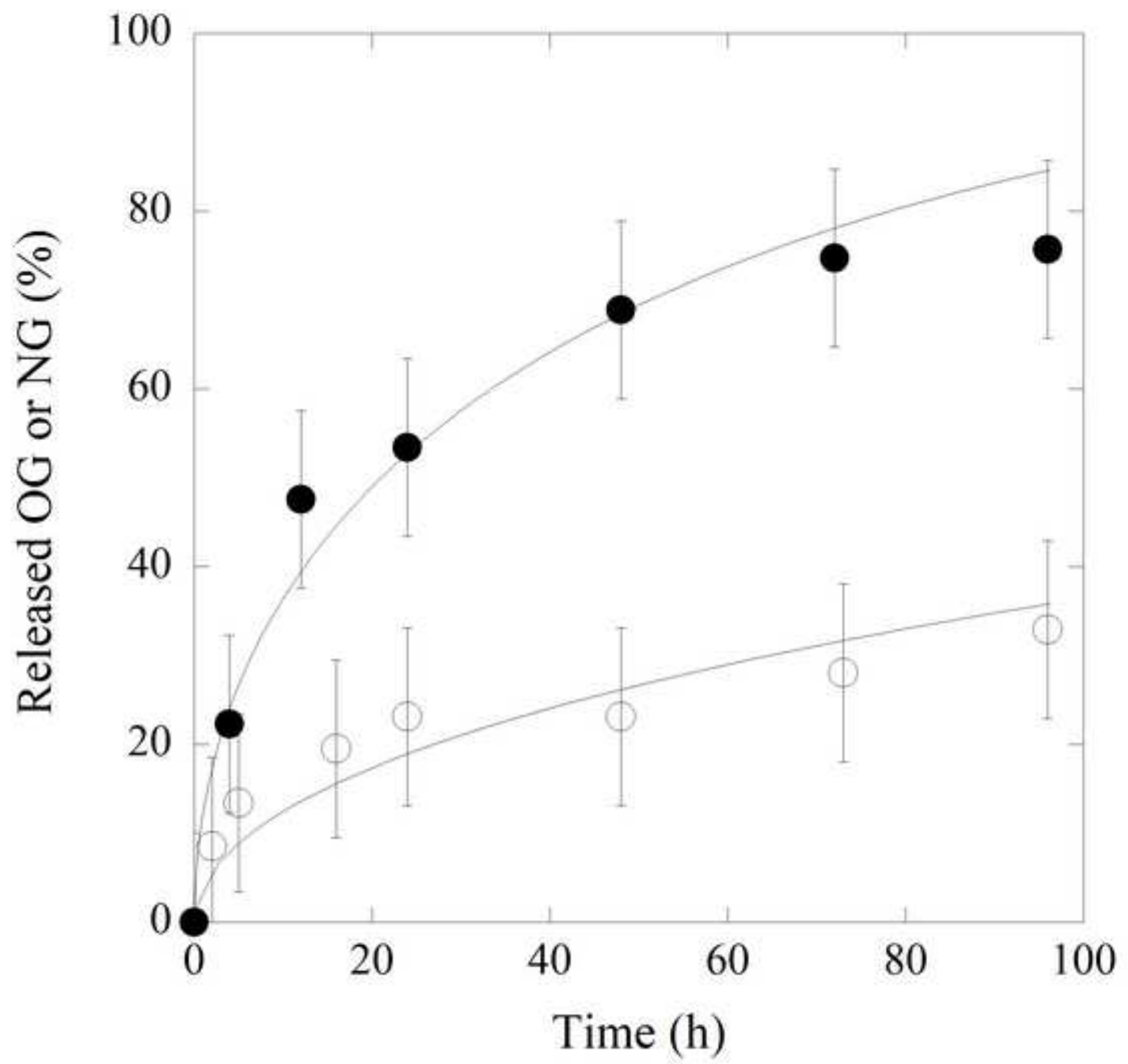


Click here to download high resolution image

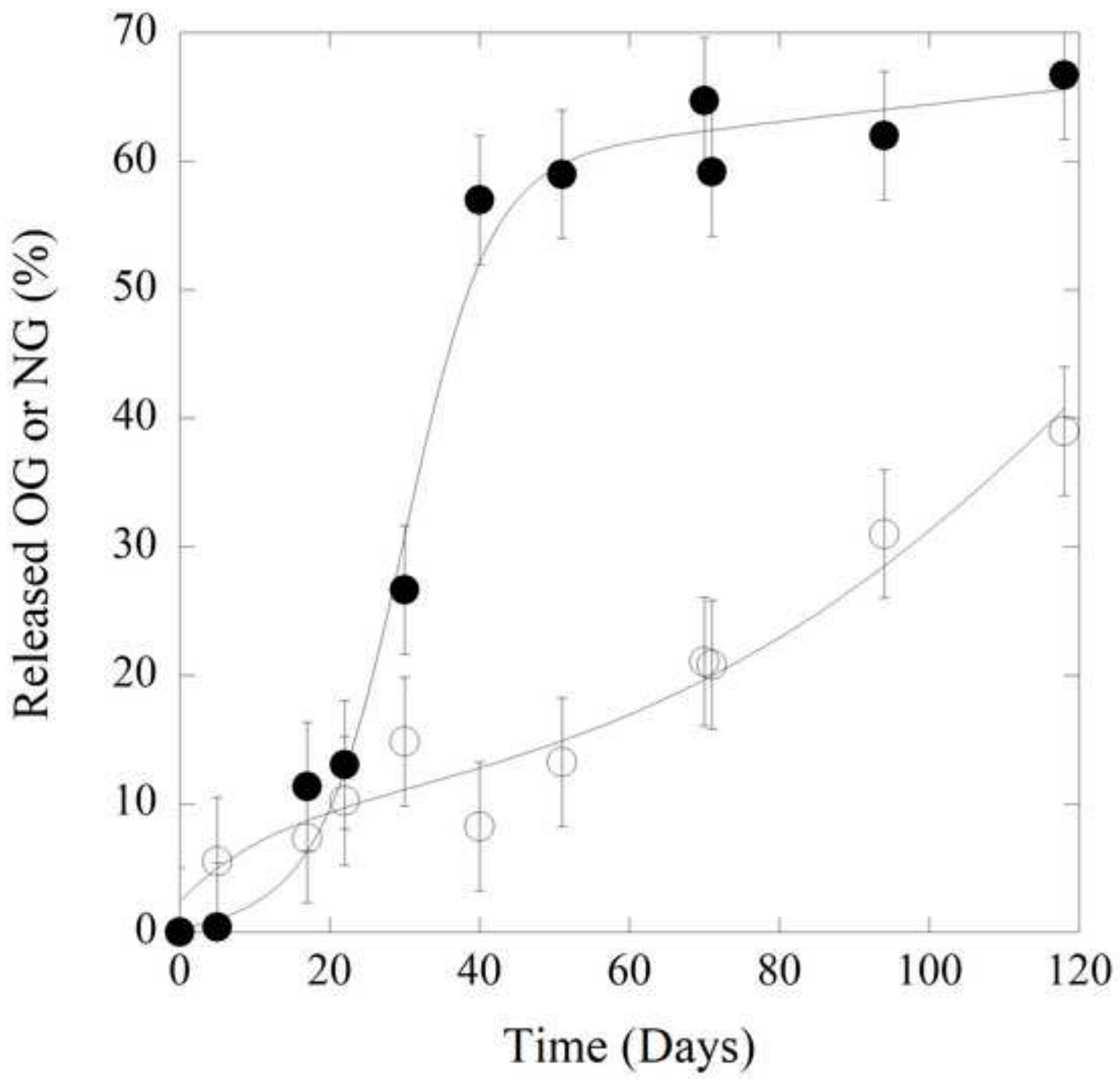


Click here to download high resolution image

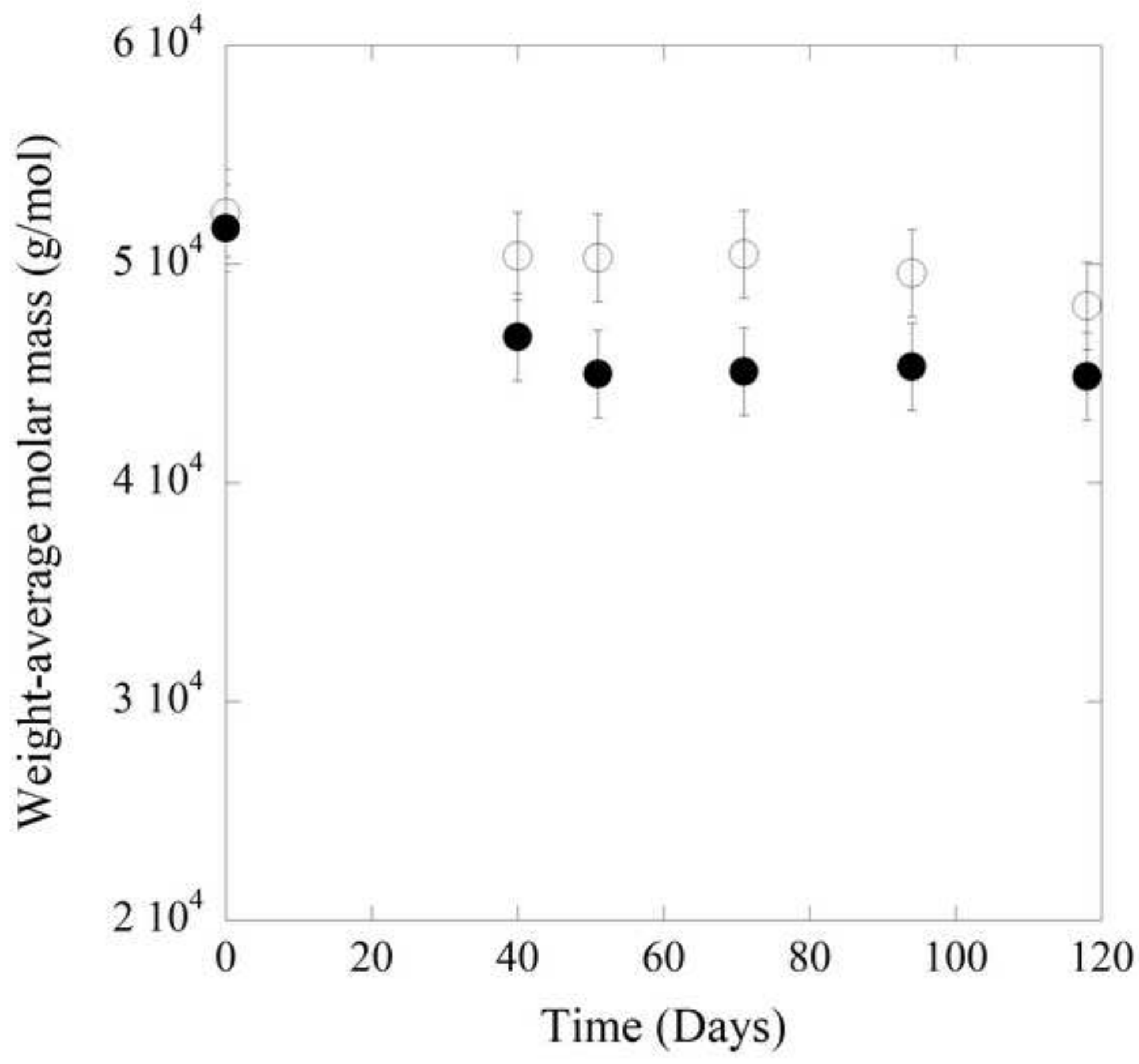




\title{
Process conditions for preparing well-defined nano- and microparticles as delivery systems of alkyl gallates
}

\author{
Asma Chebil ${ }^{\mathrm{a}}$, Denis Funfschilling ${ }^{\mathrm{b}, 1}$, Jean-Luc Six ${ }^{\mathrm{a}}$, Cécile Nouvel ${ }^{\mathrm{a}, 2}$, Alain Durand ${ }^{\mathrm{a}}$, Michèle \\ Léonard $^{\mathrm{a}, *}$
}

\section{Figure captions:}

Fig. 1. Chemical structure of hydrophobically modified dextran $\left(\operatorname{DexC}_{6}-\tau\right)$.

Fig. 2. General scheme of nano- and microparticle preparation.

Fig. 3. Surface-average diameter of nanoparticles after the washing step as a function of the maximal surface coverage of intermediate oil-in-water emulsion droplets. Open circles: variation of $\mathrm{DexC}_{6}-20$ concentration, solid circles: variation of $\mathrm{EA}$ volume, diamonds: variation of PLA concentration (for other experimental conditions see Table 2).

Fig. 4. Characteristic dimensions of the system for producing microparticles by mechanical agitation.

Fig. 5. Optical micrograph of PLA microparticles prepared using mechanical stirring (100 mg/mL PLA in EA, $4 \mathrm{~mL}$ of aqueous phase, see Table 3).

Fig. 6. Schematic representation of the flow-focusing microfluidic system used for preparing microparticles (left) and optical micrograph $5 \times$ magnification with dimensions and flows (right).

Fig. 7. TEM micrograph of microparticles prepared using a microfluidic flow-focusing system after freeze-drying and reconstitution (particles elaborated with $Q_{\mathrm{d}}=0.3 \mathrm{~mL} / \mathrm{h}$ and $Q_{\mathrm{c}}=6 \mathrm{~mL} / \mathrm{h}$ ).

Fig. 8. Solubility of OG (solid circles) and NG (open circles) in aqueous solutions of $\mathrm{DexC}_{6}-21$ and $\mathrm{DexC}_{6}-18$, respectively. 
Fig. 9. TEM micrograph of nanoparticles produced by sonication of $2 \mathrm{~mL}$ of EA containing 50 $\mathrm{mg} / \mathrm{mL}$ PLA and $10 \mathrm{~mL}$ of water containing $10 \mathrm{mg} / \mathrm{mL} \operatorname{DexC}_{6}-16$.

Fig. 10. Amounts of OG released from OG1 (solid circles) and NG released from NG1 (open circles) nanoparticles (see Table 5 and 6 for particle characteristics). Lines are curve fittings using Fick's equation.

Fig. 11. Amounts of OG released from OG1-m (solid circles) and NG released from NG1-m (open circles) microparticles (see Table 7 for details). Lines are curve fittings using the Gallagher and Corrigan equation.

Fig. 12. Weight-average molar mass of PLA contained in OG-loaded (solid circles) and NG-loaded (open circles) microparticles during release in Tris/HCl buffer $\mathrm{pH} 8.5$.

Fig. 13. Optical micrographs of fresh and swollen microparticles. OG1-m particles $\left(W_{\mathrm{GO}}^{i}=20\right.$ wt\%) immediately after preparation (a) and after 3 months in Tris/HCl buffer $\mathrm{pH} 8.5$ (b); NG1-m particles $\left(W_{\mathrm{GN}}^{i}=20 \mathrm{wt} \%\right)$ immediately after preparation (c) and after 3 months in Tris/ $\mathrm{HCl}$ buffer pH 8.5 (d). 


\title{
Process conditions for preparing well-defined nano- and microparticles as delivery systems of alkyl gallates
}

\author{
Asma Chebil $^{\mathrm{a}}$, Denis Funfschilling ${ }^{\mathrm{b}, 1}$, Jean-Luc Six ${ }^{\mathrm{a}}$, Cécile Nouvel ${ }^{\mathrm{a}, 2}$, Alain Durand ${ }^{\mathrm{a}}$, Michèle Léonard ${ }^{\mathrm{a}, *}$
}

\section{Tables}

Table 1. Surface-average diameter and Span of nanoparticles as a function of the $\mathrm{DexC}_{6}-\tau$ substitution ratio after evaporation and after washing.

\begin{tabular}{cccccc} 
& After evaporation & \multicolumn{4}{c}{ After washing } \\
\hline$\tau(\%)$ & $\begin{array}{c}D[3,2] \\
(\mathrm{nm})\end{array}$ & Span & $\begin{array}{c}D[3,2] \\
(\mathrm{nm})\end{array}$ & Span & $\begin{array}{c}\Gamma \pm 0.5 \\
\left(\mathrm{mg} / \mathrm{m}^{2}\right)\end{array}$ \\
\hline 16 & 87 & 1.0 & 94 & 0.9 & 3.4 \\
20 & 80 & 1.0 & 83 & 1.1 & 3.3 \\
22 & 98 & 1.0 & 112 & 1820 & $\mathrm{ND}^{\mathrm{a}}$ \\
\hline \multicolumn{3}{c}{ ND: not determined. }
\end{tabular}


Table 2. Effect of various processing parameters of emulsion/solvent evaporation with sonication on the characteristics of PLA particles (after evaporation and after washing).

\begin{tabular}{|c|c|c|c|c|c|c|}
\hline \multicolumn{3}{|c|}{ Formulation parameters $^{\mathrm{a}}$} & \multicolumn{2}{|c|}{ After evaporation } & \multicolumn{2}{|c|}{ After washing } \\
\hline $\begin{array}{c}{[\text { PLA] }} \\
(\mathrm{mg} / \mathrm{mL})\end{array}$ & $\begin{array}{l}V_{\mathrm{EA}} \\
(\mathrm{mL})\end{array}$ & $\begin{array}{c}{\left[\mathrm{DexC}_{6}-20\right]} \\
(\mathrm{mg} / \mathrm{mL})\end{array}$ & $\begin{array}{c}D[3,2] \\
(\mathrm{nm})\end{array}$ & Span & $\begin{array}{c}S_{\mathrm{p}} \\
\left(\mathrm{m}^{2} / \mathrm{g}\right)\end{array}$ & $\begin{array}{c}\Gamma \\
\left(\mathrm{mg} / \mathrm{m}^{2}\right)\end{array}$ \\
\hline 25 & \multirow{6}{*}{2} & \multirow{6}{*}{10} & 86 & 0.8 & 62 & 2.7 \\
\hline 50 & & & 81 & 1.0 & 57 & 2.5 \\
\hline 100 & & & 96 & 1.1 & 47 & 2.3 \\
\hline 150 & & & 140 & 1.4 & 36 & 2.5 \\
\hline 200 & & & 207 & 4.3 & 16 & 3.0 \\
\hline 250 & & & 350 & 12.4 & 13 & 3.3 \\
\hline \multirow{5}{*}{50} & 1 & \multirow{5}{*}{10} & 86 & 0.8 & 62 & 2.7 \\
\hline & 2 & & 81 & 1.0 & 57 & 2.5 \\
\hline & 3 & & 104 & 1.2 & 48 & 2.2 \\
\hline & 6 & & 152 & 1.2 & 27 & 2.0 \\
\hline & 8 & & 242 & 3.9 & 22 & 2.1 \\
\hline \multirow{5}{*}{50} & \multirow{5}{*}{6} & 20 & 101 & 1.2 & ND & 2.0 \\
\hline & & 10 & 152 & 1.2 & 27 & 2.0 \\
\hline & & 5 & 255 & 1.7 & 16 & 1.9 \\
\hline & & 2 & 448 & 1.7 & 12 & 2.2 \\
\hline & & 1 & 649 & 78 & 8 & 2.1 \\
\hline
\end{tabular}

${ }^{a}$ Other processing parameters: $10 \mathrm{~mL}$ of aqueous phase, power input of sonication $60 \mathrm{~W}$ during 2 min in pulsed mode. 
Table 3. Effect of various processing parameters of emulsion/solvent evaporation with magnetic stirring on the characteristics of PLA particles.

\begin{tabular}{|c|c|c|c|c|c|}
\hline \multicolumn{3}{|c|}{ Formulation parameters $^{\mathrm{a}}$} & \multicolumn{3}{|c|}{ After evaporation } \\
\hline $\begin{array}{c}{[\mathrm{PLA}]} \\
(\mathrm{mg} / \mathrm{mL})\end{array}$ & $\begin{array}{l}\text { Aqueous phase } \\
(\mathrm{mL})\end{array}$ & $\begin{array}{c}\text { Agitation speed } \\
(\mathrm{rpm})\end{array}$ & $\begin{array}{c}d(0.5) \\
\mu \mathrm{m}\end{array}$ & $\begin{array}{l}D[3,2] \\
(\mu \mathrm{m})\end{array}$ & Span \\
\hline 75 & & & 276 & 34 & 1.3 \\
\hline 100 & 10 & 500 & 298 & 262 & 1.3 \\
\hline $150^{\mathrm{b}}$ & & & 362 & 138 & 1.8 \\
\hline \multirow{3}{*}{100} & \multirow{3}{*}{10} & 500 & 252 & 177 & 1.2 \\
\hline & & 1000 & 132 & 99 & 1.1 \\
\hline & & 1300 & 140 & 108 & 1.3 \\
\hline \multirow{4}{*}{100} & 10 & \multirow{4}{*}{1000} & 110 & 91 & ND \\
\hline & 8 & & 138 & 99 & ND \\
\hline & 6 & & 226 & 161 & 1.5 \\
\hline & 4 & & 291 & 282 & ND \\
\hline
\end{tabular}

${ }^{a}$ Other conditions: PLA dissolved in $2 \mathrm{~mL}$ of EA; $5 \mathrm{mg} / \mathrm{mL} \mathrm{DexC}{ }_{6}-16$ in aqueous phase; 30 min emulsification.

${ }^{\mathrm{b}}$ Polymer deposit formed on the magnetic barrel and was removed before size measurement. 
Table 4. Effect of process parameters on the characteristics of microparticles obtained using a flow-focusing microfluidic device.

\begin{tabular}{cccccc}
\hline & \multicolumn{2}{c}{ Flow rates $^{\mathrm{a}}$} & & After dilution \\
$Q_{\mathrm{c}}$ & $Q_{\mathrm{d}}$ & $Q_{\mathrm{d}} / Q_{\mathrm{d}}$ & $d(0.5)$ & $D[3,2]$ & Span \\
$(\mathrm{mL} / \mathrm{h})$ & $(\mathrm{mL} / \mathrm{h})$ & & $(\mu \mathrm{m})$ & $(\mu \mathrm{m})$ & 7.5 \\
\hline 4 & & 13.3 & 6 & 0.8 & 1.3 \\
5 & 0.3 & 16.7 & 28 & 1.2 & 0.7 \\
6 & & 20.0 & 22 & 21 & 0.5 \\
\hline
\end{tabular}

${ }^{\mathrm{a}}$ Other conditions: PLA $10 \mathrm{mg} / \mathrm{mL}$ in EA, $5 \mathrm{mg} / \mathrm{mL} \mathrm{DexC} 6_{6}-17$ in water.

Table 5. Effect of processing parameters on the characteristics of AG-loaded PLA nanoparticles.

\begin{tabular}{|c|c|c|c|c|c|c|c|c|c|}
\hline \multicolumn{3}{|c|}{ Formulation parameters $^{\mathrm{a}}$} & \multicolumn{3}{|c|}{ Before washing } & \multicolumn{4}{|c|}{ After washing } \\
\hline Sample $^{\mathrm{b}}$ & $\begin{array}{l}W_{\mathrm{AG}}^{i}{ }^{\mathrm{c}} \\
(\mathrm{wt} \%)\end{array}$ & $\begin{array}{l}M_{\mathrm{tot}}{ }^{\mathrm{d}} \\
(\mathrm{mg})\end{array}$ & $\begin{array}{c}d(0.5) \\
(\mathrm{nm})\end{array}$ & $\begin{array}{c}D[3,2] \\
(\mathrm{nm})\end{array}$ & Span & $\begin{array}{c}d(0.5) \\
(\mathrm{nm})\end{array}$ & $\begin{array}{c}D[3,2] \\
(\mathrm{nm})\end{array}$ & Span & $\begin{array}{l}\Gamma( \pm 0.5) \\
\left(\mathrm{mg} / \mathrm{m}^{2}\right)\end{array}$ \\
\hline OG1 & 3 & 200 & 134 & 116 & 1.3 & 146 & 126 & 1.2 & 2.0 \\
\hline OG2 & 20 & 50 & 107 & 101 & 1.1 & 99 & 91 & 1.1 & 2.4 \\
\hline OG3 & 20 & 100 & 91 & 80 & 1.1 & 91 & 80 & 1.1 & 2.6 \\
\hline OG4 & 20 & 200 & 108 & 96 & 1.4 & 113 & 99 & 1.2 & 2.0 \\
\hline OG5 & 20 & 300 & 126 & 108 & 1.5 & 128 & 114 & 4.4 & 3.0 \\
\hline OG6 & 30 & 100 & 96 & 86 & 1.2 & 120 & 116 & 158.0 & 2.5 \\
\hline OG7 & 30 & 200 & 102 & 91 & 1.3 & 935 & 364 & 11.0 & 2.9 \\
\hline NG1 & 3 & 200 & 126 & 122 & 0.9 & 117 & 109 & 1.2 & 2.5 \\
\hline NG2 & 20 & 50 & 102 & 94 & 1.2 & 105 & 96 & 1.1 & 2.5 \\
\hline NG3 & 20 & 100 & 94 & 86 & 1.0 & 113 & 103 & 1.8 & 2.6 \\
\hline NG4 & 20 & 200 & 101 & 89 & 1.2 & 193 & 196 & 6.8 & 4.2 \\
\hline NG5 & 20 & 300 & 128 & 113 & 1.2 & 230 & 264 & 36.7 & 4.1 \\
\hline
\end{tabular}

${ }^{a}$ Other conditions: $10 \mathrm{~mL} \mathrm{H}_{2} \mathrm{O}$ containing $10 \mathrm{mg} / \mathrm{mL} \mathrm{DexC}_{6}-18$, sonication output: $60 \mathrm{~W}, 2 \mathrm{~min}$, pulsed mode.

${ }^{\mathrm{b}}$ OGxxx $=$ OG loaded nanoparticles, NGxxx $=$ NG loaded nanoparticles.

${ }^{\mathrm{c}} W_{\mathrm{AG}}^{i}$ : initially loaded weight fraction of AG in the PLA+AG mixture.

${ }^{\mathrm{d}} M_{\mathrm{tot}}$ : total mass of PLA+AG dissolved in $2 \mathrm{~mL}$ EA. 
Table 6. Encapsulation parameters of OG and NG in nanoparticles.

\begin{tabular}{cccc}
\hline Sample & $\begin{array}{c}\text { Encapsulation ratio } \\
(\text { mg SA/g PLA })\end{array}$ & $\begin{array}{c}E E^{\mathrm{a}} \\
(\%)\end{array}$ & $\begin{array}{c}W^{e}{ }_{\mathrm{AG}}^{\mathrm{b}} \\
(\mathrm{wt} \%)\end{array}$ \\
\hline OG1 & 22 & 69.8 & 2.1 \\
OG2 & 43 & 18.0 & 4.1 \\
OG3 & 84 & 33.4 & 7.7 \\
OG4 & 101 & 38.7 & 9.2 \\
OG5 & 126 & 48.5 & 11.2 \\
OG6 & 132 & 29.1 & 11.7 \\
OG7 & 189 & 43.9 & 15.9 \\
NG1 & 17 & 54.3 & 1.7 \\
NG2 & 52.3 & 20.0 & 4.9 \\
NG3 & 84 & 34.5 & 7.7 \\
NG4 & 136 & 54.3 & 12.0 \\
NG5 & 219 & 89.8 & 18.0 \\
\hline
\end{tabular}

${ }^{a}$ Encapsulation efficiency.

${ }^{\mathrm{b}} W_{\mathrm{AG}}^{e}$ : weight fraction of AG encapsulated into the recovered nanoparticles. 
Table 7. Effect of processing parameters on the characteristics of AG-loaded PLA microparticles obtained after mechanical agitation.

\begin{tabular}{cccccccc}
\hline Sample $^{\mathrm{a}}$ & $\begin{array}{c}W_{\mathrm{AG}}^{\mathrm{i}}{ }^{\mathrm{b}} \\
(\%)\end{array}$ & $\begin{array}{c}d(0.5) \\
(\mu \mathrm{m})\end{array}$ & $\begin{array}{c}D[3,2] \\
(\mu \mathrm{m})\end{array}$ & $\begin{array}{c}\text { Span } \\
(\mathrm{mg} \mathrm{SA} / \mathrm{g} \text { PLA })\end{array}$ & $\begin{array}{c}E E^{\mathrm{c}} \\
(\%)\end{array}$ & $\begin{array}{c}W^{e}{ }_{\mathrm{AG}}^{\mathrm{d}} \\
(\mathrm{wt} \%)\end{array}$ \\
\hline OG1-m & 20 & 469 & 149 & 1.1 & 237.5 & 95 & 19.2 \\
OG2-m & 30 & 616 & 185 & 0.4 & 380 & 91 & 27.5 \\
\hline NG1-m & 20 & 417 & 206 & 1.0 & 227.5 & 91 & 18,5 \\
\hline
\end{tabular}

${ }^{\mathrm{a}}$ Other conditions: $2 \mathrm{~mL}$ EA $+200 \mathrm{mg}(\mathrm{PLA}+\mathrm{AG}), 4 \mathrm{~mL} \mathrm{DexC} 6^{-17}(5 \mathrm{mg} / \mathrm{mL})$.

${ }^{\mathrm{b}} W_{\mathrm{AG}}^{i}$ : Initial weight fraction of AG in the load.

${ }^{c}$ Encapsulation efficiency.

${ }^{\mathrm{d}} W_{\mathrm{AG}}^{e}$ : weight fraction of AG encapsulated into the recovered microparticles. 